\title{
Boosting Just-in-Time Supply Chain Innovation through Additive Manufacturing: A Transdisciplinary Educational Experience
}

\author{
Aldana M., Anselmi P. D. S., Ayala M., Burns J., Cogdell R., Dilallo C., Drane L., Estevane \\ E., Ethridge B., Fenn K., Gómez, F., Griffith K., Hrechko B., Hudyncia H., Leblanc T., \\ Lugo C. E., McFather E., Miller G., Oneal C., Suesens J., Tocquigny C.
}

Gulbulak U. and Ertas A. (instructors of the AM course), Texas Tech University, Mechanical Engineering, Lubbock, Texas 79409,Email:Utku.Gulbulak@ttu.edu; atila.ertas@ttu.edu

Received 7 October, 2019; Revised 19 November, 2019 Accepted 22 November, 2019

Copyright (C) 2019 by the authors. This is an open access article distributed under the Creative Commons Attribution License (https://creativecommons.org/licenses/by/4.0/), which permits unrestricted use, distribution, and reproduction in any medium, provided the original work is properly cited.

Available online 24 November, 2019 at www.atlas-journal.org, doi: 10.22545/2019/0129

of his student project gathers together a diversity of experience and study in the development of this paper - draws together a variety of transdisciplinary fields on Just in Time (JIT) supply chain integration with additive manufacturing (AM). The impact of AM on JIT supply chain has been investigated in food, steel, bio, and vehicle industries. Students shared knowledge is presented and discussed. Collective Intelligence Management Workshops (CIMW) on the research topics of five research teams (total 20 students) have been organized. students learned how to implement transdisciplinary research process and learned knowledge generation $\&$ integration.

Keywords: Additive manufacturing, Just in time supply change, transdisciplinary research, shared knowledge, collective intelligance.

\section{Introduction}

Since the 1700's manufacturing was mainly limited to traditional machining methods such as turning and milling. These machining methods have governed the manufacturing industry for more than 100 years and have influenced designer's way of thinking towards form and function. Even though these traditional machining techniques have significantly improved in precision, cost, and productivity they hold characteristic limitations on fabrication of complex parts and shapes. With the introduction of Additive Manufacturing (AM), complexity in prod- 
Aldana M., Anselmi P. D. S., Ayala M., Burns J., Cogdell R., Dilallo C., Drane L., Estevane E., Ethridge B., Fenn K., Gómez, F., Griffith K., Hrechko B., Hudyncia H., Leblanc T., Lugo C. E., McFather E., Miller G., Oneal C., Suesens J., Tocquigny C., Gulbulak U., Ertas, A.

Boosting Just-in-Time Supply Chain Innovation through Additive Manufacturing: A Transdisciplinary Educational Experience

uct design comes "free" as product components are created by melting thin layers of material powder in successive overlapping $2 \mathrm{D}$ shapes creating a $3 \mathrm{D}$ part [1]. As traditional manufacturing experienced many years multidisciplinary and interdisciplinary activities, the emergence of additive manufacturing is moving manufacturing toward a transdisciplinary activity [2].

The availability of low-cost AM machines has created the manufacturer movement which has inspired the general public with ability to create, design and manufacture variety of parts and products. The biggest solution offered by additive manufacturing is the capability to print Just-in-Time (JIT) parts and products on demand. However, AM requires further research to overcome some of the technical challenges such as materials and processing.

\section{Supply Chain}

Supply chain (SC) is the sequence of processes that transform raw materials to finished goods - and then to the distribution of the finished goods. Supply chain managemenis shown in Figure 1.

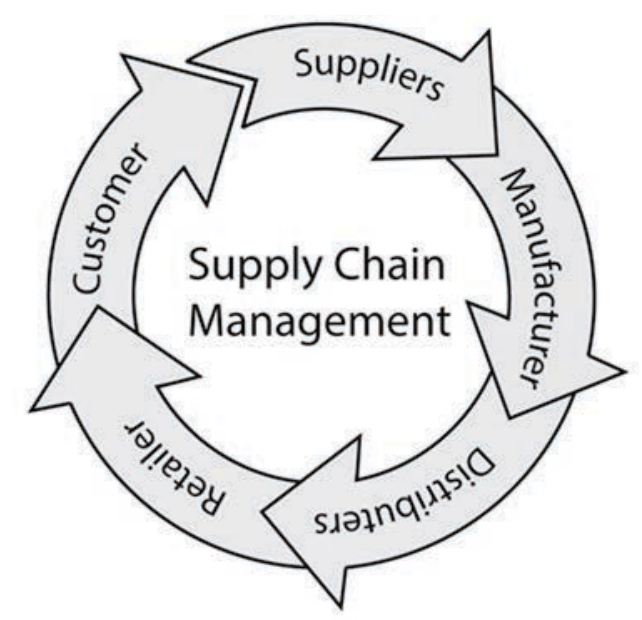

Figure 1: Supply chain management.

"Supply chain management, techniques with the aim of coordinating all parts of SC from supplying raw materials to delivering and/or resumption of products, tries to minimize total costs with respect to existing conflicts among the chain partners. An example of these conflicts is the interrelation between the sale department desiring to have higher inventory levels to fulfill demands and the warehouse for which lower inventories are desired to reduce holding costs." [3]

\section{Just-In-Time Supply Chain in Lean Manufacturing}

The objective of Just-In-Time (JIT) is to produce and deliver finished products 'just in time' to be sold. Using JIT philosophy, companies keep to increase efficiency and decrease waste by receiving goods only as they are needed in the production process. This method requires producers to estimated demand almost precisely.

\section{Just-In-Time Part Printing}

The Just-In-Time Part Printing (JITPP) is a new trend to improve productivity via reducing cost and improving quality: maybe the greatest solution offered by additive manufacturing is the capability to print JIT parts on demand. For this process, a part and required tooling are digitized and stored in a file management system within a virtual inventory. The parts and tooling then can be produced with much shorter lead times than traditional way with less expensive "minimum order" volume requirements [4].

Supply Chain Transformation through Additive Manufacturing

To advance supply chains through AM can offer lower costs, less risks and greater flexibility and agility. Consider a customer who needs a particular low-demand service part as soon as possible-can't wait for shipping from a central warehouse, or can't wait for fabrication by supplier. This new specific part can be simply printed through AM on the spot. Think also this specific part fails at a remotely located facility. An on-site 3D printer might fabricate this part and allow barely a stop in productivitypossibly saving thousands of dollars per hour in facility downtime (for more information see reference [5]). AM can Improve SC by [5]:

- Reducing material use for leaner manufacturing

- Simplifying manufacturing processes and reducing costs

- Reducing risk by providing a contingency plan

- Increasing process flexibility 
Aldana M., Anselmi P. D. S., Ayala M., Burns J., Cogdell R., Dilallo C., Drane L., Estevane E., Ethridge B., Fenn K., Gómez, F., Griffith K., Hrechko B., Hudyncia H., Leblanc T., Lugo C. E., McFather E., Miller G., Oneal C., Suesens J., Tocquigny C., Gulbulak U., Ertas, A.

Boosting Just-in-Time Supply Chain Innovation through Additive Manufacturing: A Transdisciplinary Educational Experience

- Reshaping SC networks into distributed production networks

- Decreasing the capital cost of entry into new markets

\subsection{Transdiscipline}

Multidisciplinary activities engage researchers from diverse disciplines working independently, each from their own discipline specific perspective, to solve a common problem. Multidisciplinary teams do cross discipline boundaries; however, they remain narrow to the framework of disciplinary research. In interdisciplinary activities, researchers from different disciplines work together on common problems by exchanging methods, tools, concepts and processes among them to find integrated solutions. Both multidisciplinary and interdisciplinary activities cross discipline boundaries but their goal remains within the framework of disciplinary research [6].

Across academies, many scholars have been contributed to the transdisciplinarity and integrated research concepts. Numerous articles have been published by Basarab Nicolescu on the scientific transdisciplinary research approaches $[7,8]$. Stokols outlined programmatic directions for the scientific study of transdisciplinary research and community action [9]. "Interdisciplinary and transdisciplinary research performance and evaluation are both generative processes of harvesting, capitalizing, and leveraging multiple kinds of expertise." [Klein, 10]' "A research becomes transdisciplinarty by transcending and integrating disciplinary paradigms in order to address socially (as opposed to academically) relevant issues." [Pohl , 11] All cross the world, transdisciplinary approaches should be commonly applied in order to address the environmental issues that we should be concerned about (Lawrence, J. R., [12]).

McGregor introduced four philosophical axioms (ontology, epistemology, logic and axiology) underpinnings of the transdisciplinary research methodology. She stated that "if scholars were more familiar with transdisciplinarity, they would be more inclined to embrace it in their research. Their scholarship would focus on the common good (a Sacred, normative framework); respect the diversity of perspectives; honor and accommodate complexity; and strive to integrate abstract (academic) with case-specific (lifeworld) knowledge." [13] Transdisciplinary practice and informational thinking are essential ways of helping the common good [Brenner, 14]. Gehlert articulate the challenges to implementing transdisciplinary education and training and recommended elements of a successful transdisciplinary educational program in health [15].

"Artful doing is a genuine transdisciplinary practice that is at once rooted in sensitivity, intuition as well as analytical rationality. It organically links analytical and feelings intelligence with the intelligence of the body." [Hans, 16] Universities should become a multidimensional community that requires a profound transformation toward transdisciplinarity, involving the ecologization and contextualization of knowledge (Adame, [17]).

Transdisciplinary educational approaches have been extensively studied by Ertas [6, 18-20]. Transdisciplinary collaboration has a big promise to speed the rate at which research can provide to the understanding of the complex problem, speed up the pace of new discoveries, and create new knowledge. Transdisciplinarity provides a good framework and add to the current approaches for collective intelligence to solve society's unstructured problems [21].

Transdisciplinary research activities/process can be defined as: research effort creating "collective impact" through expertise from a wide range of organizations to generate new knowledge through "collective intelligence" and conduct useful research for the solution of unstructured (having no obvious solution) comprehensive and conflicting technical/social issues, that benefits society.

\section{Goal and Methodology}

\subsection{Goal}

Students in a senior elective design class (Additive Manufacturing) were asked to work on a research project for the class. The research project was: "create your own just in time supply chain and discuss how supply chain innovation can boost through additive manufacturing." Six research project teams of three to five students in each team were organized to create their own research problem from any transdisciplinary fields. During the class, each team introduced their project proposal (concepts) about the project that they will be exploring. The selected transdisciplinary fields by the research teams were: 
Aldana M., Anselmi P. D. S., Ayala M., Burns J., Cogdell R., Dilallo C., Drane L., Estevane E., Ethridge B., Fenn K., Gómez, F., Griffith K., Hrechko B., Hudyncia H., Leblanc T., Lugo C. E., McFather E., Miller G., Oneal C., Suesens J., Tocquigny C., Gulbulak U., Ertas, A.

Boosting Just-in-Time Supply Chain Innovation through Additive Manufacturing: A Transdisciplinary Educational

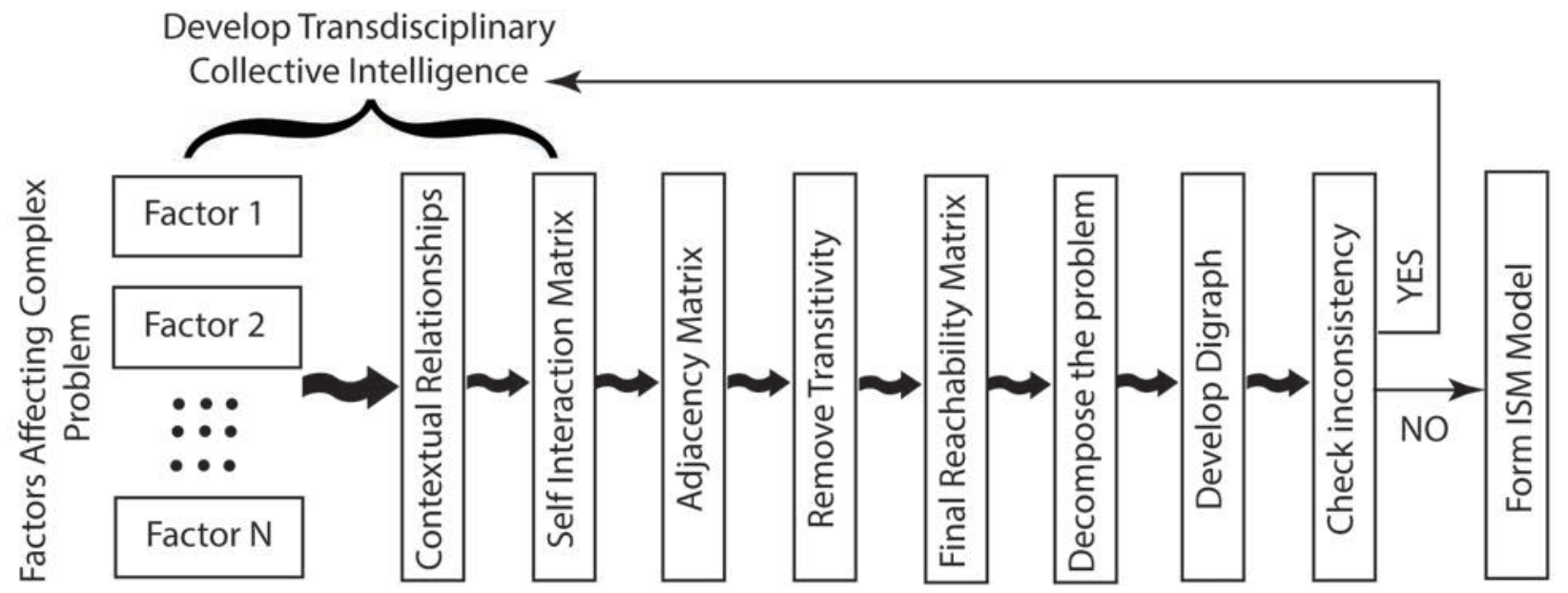

Figure 2: Sequence of activities to develop ISM model.

steel, food, bio, and vehicle industries.

\subsection{Methodology}

JIT method requires sophisticated planning and considerable experience in this field to overcome complex issues. The most important issues of the JIT supply chain were identified as follows [22]:

1. high variance in demand and supply

2. high machine setup time

3. lack of flexibility of manufacturing system

4. supplier capacity constraints

5. line stoppage

6. poor product quality

7. optimization of product variety

8. high production cost.

\subsection{Interpretive Structural Modeling (ISM)}

Interpretive Structural Modeling (ISM), a methodology for dealing with complex issues was proposed by Warfield in 1973 [23] that provides fundamental understanding of how various parameters relevant to the complex problem interrelated. Thus helps researchers to structure them in a meaningful manner to develop collective intelligence to overcome challenging unstructured problem problems [24].

ISM is a process used to transform a basic concept model into an organized, well-articulated model. The first step in applying the ISM model is to clearly identify the complex problem that will be examined and organize research team members to develop transdisciplinary collective intelligence (see Figure 2 ). The next step is, through team work, to analyze and determine the critical factors that are affecting the complex problem. This step requires also brainstorming and consultation with the domain experts.

The third step is to determine contextual relationship to develop structural self-interaction matrix shown in Figure 2. Using expert opinions along with research team members SSIM will be developed. As shown in Figure 2, combination of these three steps is called "Transdisciplinary Collective Intelligence."

Then the adjacency matrix, $R_{a}$ is developed by transforming SSIM into a binary matrix. Next step is check for the transitivity rule and update the matrix to obtain Reachability Matrix with Transivity, $R_{t}$. Driving power and dependence of factors are also computed in the final reachability matrix $R_{f}$ as shown in Figure 2. Summation of ones in the corresponding rows gives the driving power and the summation of ones in the corresponding columns gives the dependence. For decomposing the problem (level partition), the final reachability matrix, $R_{f}$ along with antecedents of each element of prospects are used [25]. Previously obtained driving force and dependence helps to classify the factors into groups.

Finally, the association of sets and binary relations through matrices can now be converted into graphical form by using theory of digraphs (directed graphs) [23]. More information on the ISM will be provided through case studies of this paper. 
Aldana M., Anselmi P. D. S., Ayala M., Burns J., Cogdell R., Dilallo C., Drane L., Estevane E., Ethridge B., Fenn K., Gómez, F., Griffith K., Hrechko B., Hudyncia H., Leblanc T., Lugo C. E., McFather E., Miller G., Oneal C., Suesens J., Tocquigny C., Gulbulak U., Ertas, A.

Boosting Just-in-Time Supply Chain Innovation through Additive Manufacturing: A Transdisciplinary Educational Experience

\section{Research Project Case Studies}

In this section, four research project case studies in the field of food, steel, bio, and vehicle industries industries will be discussed.

\subsection{Case Study-I: Implementing Additive Manufacturing into McDonald's Just-In-Time Supply Chain}

Student Research Team: Marvin Ayala, Fernando Gómez, Elio Lugo and Emmitt McFather

As the world's largest fast food restaurant chain, McDonald's serves over 68 million customers every day. Additionally, McDonald's employs over 375,000 people to run its 36,000 restaurants all over the world [26]. To successfully serve, manage, and employ, McDonald's has implemented the JIT-SC corporate strategy. As a result, profits have skyrocketed to about 75 million US dollars in revenue each day. This research will analyze the JIT-SC, its effects on the McDonald's franchise, and, most importantly, how additive manufacturing can contribute the growth of this market capitalization in the food service industry.

A decrease in production time/cost, waste elimination, and a successfully consistent production process are the key factors expanded upon when implementing the JIT-SC strategy. The typical business is able to find a process that works and stick with it. However, the market is constantly changing. The JIT-SC accounts for this. Finding a process that reduces inventory, improves quality, reduces production time, continuously adapts to the market, and strategically advertises to consumers is what defines this corporate strategy. The priority of JIT is to provide the very best for the customer while increasing profits and minimizing cost and waste.

Before the implementation of JIT, McDonald's was not operating at its full potential. When ordering supplies, managers had to account for busy days by overordering. As a result, extra supplies went to waste before the next, fresh shipment of supplies arrived. Burger patties were pre-cooked and remained under a heat lamp until served. At the end of the day, all unsold patties were discarded. Pre-made burgers resulted in special orders being expensive and time-taking. If a customer had an allergy or requested something specific, a completely new burger was made, extending the customer's wait time.

After the implementation of JIT, McDonald's has reduced inventory, improved quality, shortened customer wait time, and made billions of dollars in profit [27]. When ordering supplies, managers now order only what they need because burgers can be made so quickly. The estimated wait for a burger has been reduced from 11 minutes to 1 and a half minutes. The record-breaking bun toaster is a perfect example of McDonald's implementation of the JIT supply chain. To improve efficiency and maintain quality, buns are now toasted right after the customer orders. This advancement in technology also makes special orders quite easy. Since burgers no longer remain under heat lamps after being premade, a simple or complex change can be adequately accounted for in an acceptable amount of time. Unsold, pre-made burgers are no longer a concern, leading to a significant reduction in waste. While pre-made burgers were "relatively fresh," McDonald's new technologies and strategies that allow for burgers to be made immediately after the order is placed, have boosted the quality of the fast food chain and the food itself. To further success, McDonald's has invested into AM.

\subsubsection{Supply Chain Structure}

Usually, traditional manufacturing requires the confirmation of product availability before assembly. If availability can be neglected in the SC because parts will be $3 \mathrm{D}$ printed, synchronization efforts are reduced. For example, at McDonald's, if the Mic Mac burger is 3D printed with synthetic protein, the SC will not need to take into account soil exploitation as well as how long it will take for animal meat to be ready [28]. As a result, the need for planning decreases along with risks and costs.

\subsubsection{Supply Chain Inventories}

When AM is integrated, initial materials are directly used in the final product, demonstrating that there is no need for processing as everything is done through a 3D printer. Customization is typically achieved with a detailed product design either by the company or customer. The requirements of the customer are fulfilled whenever the SC combines the right, necessary components into one final product. 
Aldana M., Anselmi P. D. S., Ayala M., Burns J., Cogdell R., Dilallo C., Drane L., Estevane E., Ethridge B., Fenn K., Gómez, F., Griffith K., Hrechko B., Hudyncia H., Leblanc T., Lugo C. E., McFather E., Miller G., Oneal C., Suesens J., Tocquigny C., Gulbulak U., Ertas, A.

Boosting Just-in-Time Supply Chain Innovation through Additive Manufacturing: A Transdisciplinary Educational Experience

In a traditional supply chain, achieving fast response times required a very high inventory. Now, digital manufacturing processes eliminate the need for a high inventory. For example, McDonald's would not need to keep trillions of kilograms of meat and potatoes or livestock to satisfy customer needs. Through 3D printing, McDonald's can produce a final meal in the kitchen without contacting a supplier.

\subsubsection{Decentralized Manufacturing and Transport Times}

The use of 3D printing devices decentralizes the manufacturing process [29]. Since production can be close to the customer, final distribution and transportation times decrease at an exponential rate. In the case of McDonald's, when 3D printers are used, it will certainly be easier to transport protein and plastic (for straws and toys) from a lab directly to the restaurant; rather than transporting livestock to obtain fresh meat then transport frozen meat to the restaurant [30, 31]. Manufacturing decentralizes and the need for remote locations to transport material is almost unnecessary.

\subsubsection{Component Lead Times and Customer Responsiveness}

When a typical assembly process begins operation, the materials are gathered from one or more external suppliers. This, as a result, causes efficiency to be checked in advance because businesses don't want to order more materials than needed. With additive manufacturing, the check for efficiency is done at the end of 3D printing. The most problematic factors that can occur would be due to limited machine capacity or a defective part (it doesn't look or work as expected).

\subsubsection{Analysis of McDonald's with Interpretive Structural Model (ISM)}

By utilizing the transdisciplinary collective intelligence priciples (see Figure 2), the main factors affecting the JIT-SC with respect to AM were identified and defined as:

1. Product Quality: Improving products to ensure appropriate taste

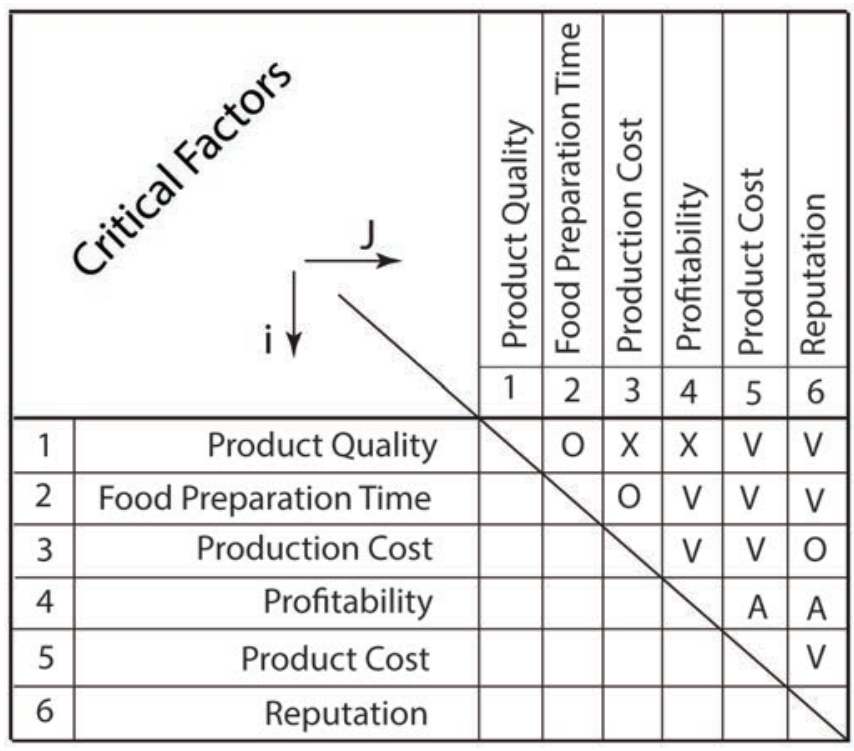

Figure 3: Structural Self-Interaction Matrix (SSIM for McDonald's).

2. Food Preparation Time: The most efficient and time saving cooking process for the customer to receive their food as fresh and as fast as possible

3. Production Cost: Appropriate cost to make products, ensuring profit

4. Profitability: The degree to which the business yields profit or financial gain

5. Product Cost: Appropriate prices for the product being sold

6. Reputation: Maintaining a good status in the market and with consumers

After defining the main contributing factors, a contextual relationship needed to be established in order to develop a structural self-interaction matrix (SSIM) (see Figure 3). The following four symbols were used to define relationships among the factors:

- V: Variable i affects variable $\mathrm{j}$

- A: Variable $\mathrm{j}$ affects variable $\mathrm{i}$

- X: Both variables, $\mathrm{i}$ and $\mathrm{j}$, affect each other

- O: No relationship between variables $i$ and $j$

After the development of the SSIM, the next matrix that can be drawn was the adjacency matrix (see Table 1). To obtain the adjacency matrix, the SSIM was transformed into a binary matrix by substituting 
Aldana M., Anselmi P. D. S., Ayala M., Burns J., Cogdell R., Dilallo C., Drane L., Estevane E., Ethridge B., Fenn K., Gómez, F., Griffith K., Hrechko B., Hudyncia H., Leblanc T., Lugo C. E., McFather E., Miller G., Oneal C., Suesens J., Tocquigny C., Gulbulak U., Ertas, A.

Boosting Just-in-Time Supply Chain Innovation through Additive Manufacturing: A Transdisciplinary Educational Experience

Table 1: Adjacency matrix.

\begin{tabular}{|l|c|c|c|c|c|c|c|}
\hline Name of the Factor & Factor \# & $\mathbf{1}$ & $\mathbf{2}$ & $\mathbf{3}$ & $\mathbf{4}$ & $\mathbf{5}$ & $\mathbf{6}$ \\
\hline Product Quality & 1 & 1 & 0 & 1 & 1 & 1 & 1 \\
\hline Food Preparation Time & 2 & 0 & 1 & 0 & 1 & 1 & 1 \\
\hline Production Cost & 3 & 1 & 0 & 1 & 1 & 1 & 0 \\
\hline Profitability & 4 & 1 & 0 & 0 & 1 & 0 & 0 \\
\hline Product Cost & 5 & 0 & 0 & 0 & 1 & 1 & 1 \\
\hline Reputation & 6 & 0 & 0 & 0 & 1 & 0 & 1 \\
\hline
\end{tabular}

Table 2: Reachability matrix with transitivity.

\begin{tabular}{|l|c|c|c|c|c|c|c|}
\hline Name of the Factor & Factor \# & $\mathbf{1}$ & $\mathbf{2}$ & $\mathbf{3}$ & $\mathbf{4}$ & $\mathbf{5}$ & $\mathbf{6}$ \\
\hline Product Quality & 1 & 1 & 0 & 1 & 1 & 1 & 1 \\
\hline Food Preparation Time & 2 & 1 & 1 & 0 & 1 & 1 & 1 \\
\hline Production Cost & 3 & 1 & 0 & 1 & 1 & 1 & 1 \\
\hline Profitability & 4 & 1 & 0 & 1 & 1 & 1 & 1 \\
\hline Product Cost & 5 & 1 & 0 & 0 & 1 & 1 & 1 \\
\hline Reputation & 6 & 1 & 0 & 0 & 1 & 0 & 1 \\
\hline
\end{tabular}

the V's, A's, X's, and O's with 0's and 1's. To aid in the understanding of the binary transformation of the SSIM, the following rules that were applied:

- $\mathrm{V}$ : the adjacency matrix entry $(\mathrm{i}, \mathrm{j})$ becomes 1 and $(\mathrm{j}, \mathrm{i})$ becomes 0

- A: the adjacency matrix entry $(\mathrm{i}, \mathrm{j})$ becomes 0 and $(\mathrm{j}, \mathrm{i})$ becomes 1

- $\mathrm{X}$ : The adjacency matrix entries $(\mathrm{i}, \mathrm{j})$ and $(\mathrm{j}, \mathrm{i})$ both become 1

- O: The adjacency matrix entries $(\mathrm{i}, \mathrm{j})$ and $(\mathrm{j}, \mathrm{i})$ both become 0

After the completion of the adjacency matrix, the reachability matrix with transitivity was created (see Table 2). The purpose of this matrix is to apply the transitivity rule. This rule states, when factor A is related to factor $\mathrm{B}$ and factor $\mathrm{B}$ is related to factor $\mathrm{C}$, then factor $\mathrm{A}$ is related to factor $\mathrm{C}$.

Once the initial reachability matrix (with transitivity) was created, the final reachability matrix can be obtained (shown in Table 3 ). In this matrix, by summing all of the 1's in each row and column, driving power and dependence can be found, respectively.

Using both the final reachability matrix and the antecedents of each element of prospects, the level partition was created. Through the consideration of the driving force and dependence found in the final reachability matrix, the factors were classified by level (see Table 4). The level positions were determined by the separation of the antecedent and reachability sets.

If a factor was in both the reachability and antecedent sets, it was classified as part of the intersection set. Following the identification of the three types of sets, each factor was filed into its own level. If all of the factors in the intersection and reachability sets of a particular factor were the same, then that factor was identified as part of the first level in the ISM hierarchy. After all the first level factors were identified, they were removed from the set, and the next level followed the same process until classification. This process was repeated until all levels were defined.

Next, the theory of digraphs was used to convert the association of sets and binary relations through matrices into a graphical form (see Figure 4). This graphical form shows a broad representation of the interrelationships between factors.

The final step taken in the analysis of the factors contributing to McDonald's JIT-SC was to create a MICMAC analysis. The MICMAC arranges factors into four clusters with respect to their driving power and dependence. The four clusters are categorized as autonomous, dependent, linkage, and independent (see Figure 5). The purpose of the MICMAC analysis is the identify the most important factors that will influence AM in McDonald's JIT supply chain.

Both the digraph (Figure 4) and the MICMAC (Figure 5) reveal the most independent factors to be food preparation time (2) and production cost (3). They are the driving factors to control the McDonald's efficiency. This seems to be highly accurate, as McDonald's is a fast-food chain. Reputation (6) is also revealed to be the most dependent factor, making sense because a restaurant's reputation depends on all factors contributing to the restaurant's success or failure. The factors in the linkage cluster have to be given great importance due to their high driving and high dependence power. Linkage cluster includes Product Quality (1), Profitability (4), and Product Cost (5). Any action on any of the factor in linkage cluster will affect the entire McDonald's supply chain.

Considering the MICMAC results, the best way to positively impact the supply chain is by upgrading the independent factors (factors 2 and 3 ) to drive the rest of the factors. AM can be a good source of 
Aldana M., Anselmi P. D. S., Ayala M., Burns J., Cogdell R., Dilallo C., Drane L., Estevane E., Ethridge B., Fenn K., Gómez, F., Griffith K., Hrechko B., Hudyncia H., Leblanc T., Lugo C. E., McFather E., Miller G., Oneal C., Suesens J., Tocquigny C., Gulbulak U., Ertas, A.

Boosting Just-in-Time Supply Chain Innovation through Additive Manufacturing: A Transdisciplinary Educational Experience

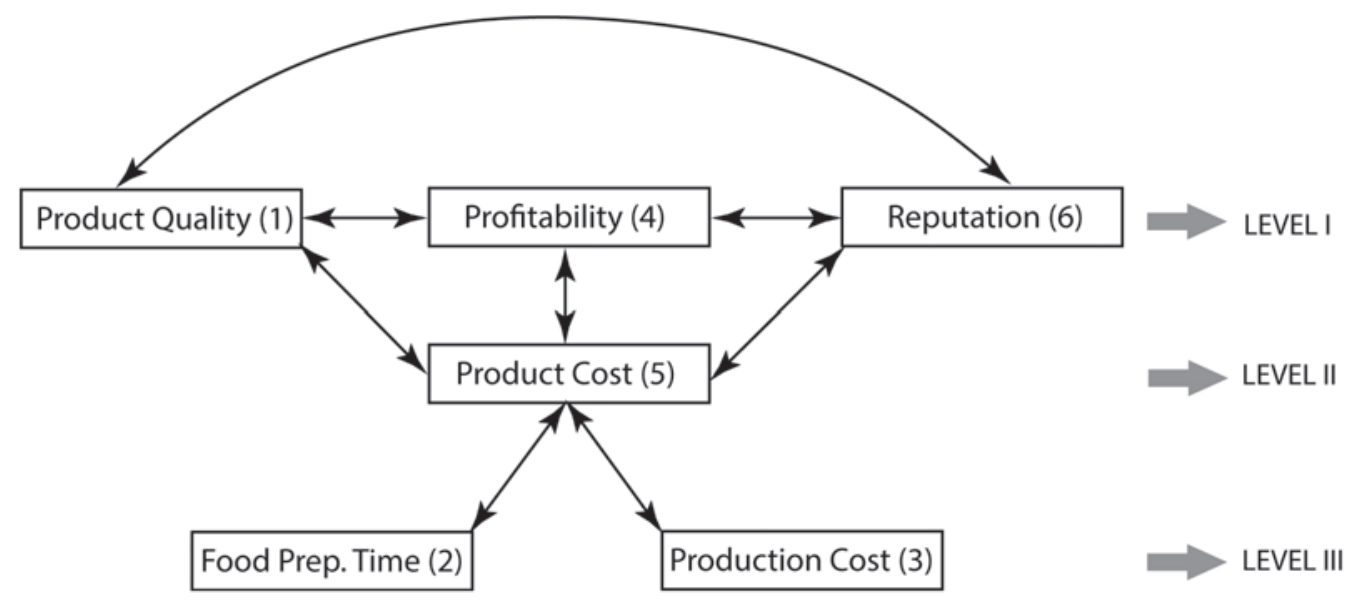

Figure 4: ISM-based model for interrelationship between factors.

Table 3: Final reachability matrix.

\begin{tabular}{|l|c|c|c|c|c|c|c|c|}
\hline Name of the Factor & Factor \# & $\mathbf{1}$ & $\mathbf{2}$ & $\mathbf{3}$ & $\mathbf{4}$ & $\mathbf{5}$ & $\mathbf{6}$ & Driving Power \\
\hline Product Quality & 1 & 1 & 0 & 1 & 1 & 1 & 1 & 5 \\
\hline Food Preparation Time & 2 & 1 & 1 & 0 & 1 & 1 & 1 & 5 \\
\hline Production Cost & 3 & 1 & 0 & 1 & 1 & 1 & 1 & 5 \\
\hline Profitability & 4 & 1 & 0 & 1 & 1 & 1 & 1 & 5 \\
\hline Product Cost & 5 & 1 & 0 & 0 & 1 & 1 & 1 & 4 \\
\hline Reputation & 6 & 1 & 0 & 0 & 1 & 0 & 1 & 3 \\
\hline & Dependence & 6 & 1 & 3 & 6 & 5 & 6 & $\sum=27$ \\
\hline
\end{tabular}

Table 4: Level partition.

\begin{tabular}{|c|l|l|l|c|}
\hline Factor \# & Reachability Set & Antecedent Set & Intersection Set & Level \\
\hline 1 & $1,3,4,5,6$ & $1,2,3,4,5,6$ & $1,3,4,5,6$ & 1 \\
\hline 2 & $1,2,5,6$ & 2 & 2 & \\
\hline 3 & $1,3,4,5,6$ & $1,3,4$ & $1,3,4$ & \\
\hline 4 & $1,3,4,5,6$ & $1,2,3,4,5,6$ & $1,3,4,5,6$ & 1 \\
\hline 5 & $1,4,5,6$ & $1,2,3,4,5$ & $1,4,5$ & \\
\hline 6 & $1,4,6$ & $1,2,3,4,5,6$ & $1,4,6$ & 1 \\
\hline \multicolumn{5}{|l}{} \\
\hline 2 & 2,5 & 2 & 2 & \\
\hline 3 & 3,5 & 3 & 3 & 2 \\
\hline 5 & 5 & $2,3,5$ & 5 & 3 \\
\hline \multicolumn{5}{|l|}{} \\
\hline 2 & 2 & 2 & 2 & 3 \\
\hline 3 & 3 & 3 & 3 & \\
\hline
\end{tabular}

improvement for food preparation time (2) as well as production cost (3). When food preparation time is reduced, there are less processes and steps for McDonald's burgers to be developed. The production cost, in the long run, is decreased as there is now only the need to spend money on 3D printers and maintenance, rather than outsourcing, livestock, transportation, legal regulations and inventory.

\subsection{Case Study-II: Impact of Additive Manufacturing on Supply Chain of a Steel Mill}

Student Research Team: Jacob Burns, Riley Cogdell and Cooper Tocquigny

The purpose of this research is to observe how JIT-SC could be optimized by implementing AM in 
Aldana M., Anselmi P. D. S., Ayala M., Burns J., Cogdell R., Dilallo C., Drane L., Estevane E., Ethridge B., Fenn K., Gómez, F., Griffith K., Hrechko B., Hudyncia H., Leblanc T., Lugo C. E., McFather E., Miller G., Oneal C., Suesens J., Tocquigny C., Gulbulak U., Ertas, A.

Boosting Just-in-Time Supply Chain Innovation through Additive Manufacturing: A Transdisciplinary Educational Experience

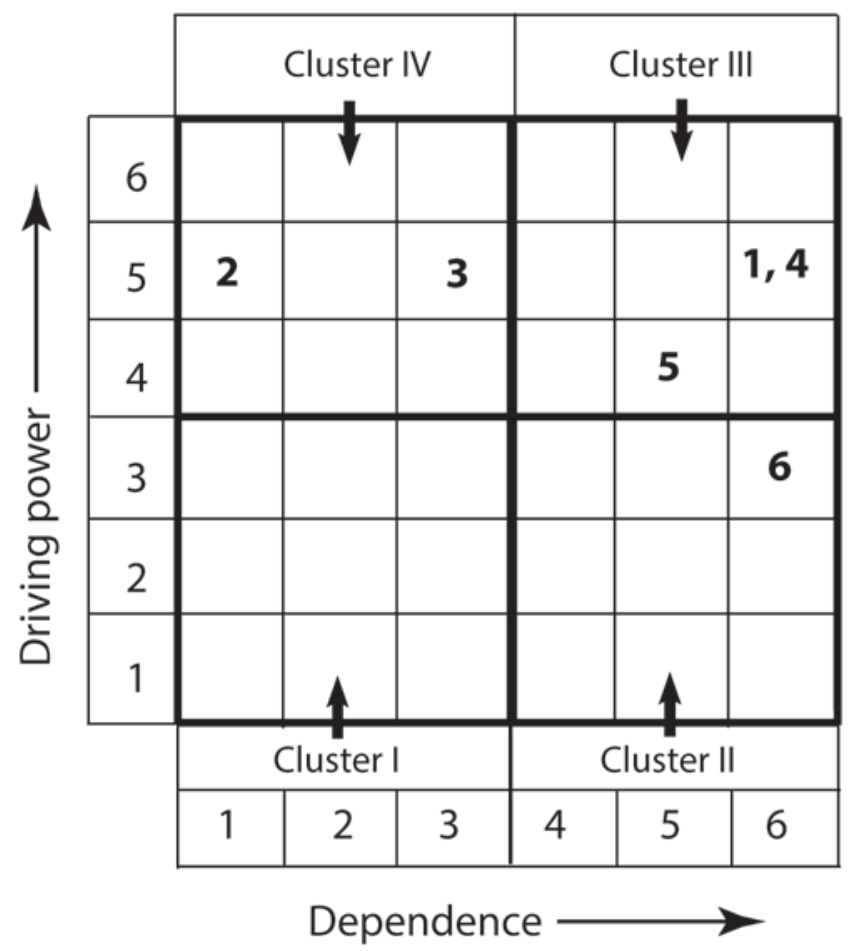

Figure 5: Driving power-dependence map (MICMAC).

the SC. As the global market grows, new techniques and methods must be developed to keep up with the demand while reducing environmental footprint and cost of production. In this part of the research, the benefits of including AM in the steel mill SC will be explored.

The modern steel industry has been one of the greatest and most influential industries in human history. Before industrialization, goods produced with steel were rare and used for special applications such as swords and cutlery. But with the introduction of the Bessemer process and other technologies brought forth during the industrial revolution, steel become a much more common material [32]. By the end of the 19th century, open-hearth steelmaking become the dominant method of steel production [33]. Not long after that, the electric arc furnace began to be used in the 1920s and is still in use today [34]. The next technological advancement in the steel industry could be here soon, with the growing popularity and viability of AM. AM has the potential to drastically change the dynamic of a SC, especially a Just-InTime-SC. Before the benefits of AM can be applied to the steel industry, a thorough understanding of its SC must be known.
The SC (see Figure 6 ) of a steel mill starts with the mining of iron ore and coal. These materials are then shipped from the mining sites directly to the steel mill. The mill then performs a process on the coal called coking, where the coal is put in a furnace to remove unwanted substances such as organic material or water. What is left is coke, a dry, porous material with a high carbon content. This coke is then used as a fuel to heat up and smelt the iron ore [35]. During this process, the iron is carbonized and creates steel. Once the steel is solidified, it can then be either hot or cold-rolled into large sheets. These sheets are then shipped via railcar to buyers for any of the nearly countless uses of steel.

The JIT-SC is one where materials are purchased, manufactured into goods, and delivered as close possible to the exact time they are needed. In the instance of a steel mill SC, raw materials are brought to the mill to be immediately made into rolled steel, and that steel are delivered as ordered shortly after it is manufactured. A JIT-SC is advantageous for any industry, as optimization of JIT minimizes delay, the turnover time between the manufacturing of goods and the selling of them. Having a JIT-SC also removes the possibility of excess goods produced, which will waste money [36]. JIT supply chains are advantageous in just about every industry, and the steel industry is no exception.

\subsubsection{Steel Mill Supply Chain ISM Analysis}

Through transdisciplinary collective intelligence process, research team decided to consider the following six critical factors affecting steel mill supply chain.

Transportation: One of the most important qualities for any business is their ability to import stock and export goods. Specifically, a standard steel mill is focused on importing the mined ore and raw materials, while exporting the newly formed steel as quickly as possible. The JIT-SC is directly dependent on the efficiency of the transportation of goods and materials. One specific component regarding transportation that the steel mill can control is weight and size. A mill can only export as much as their trucks can carry, therefore, they would want to minimize weight and size in order to fit more product onto the trucks. 
Aldana M., Anselmi P. D. S., Ayala M., Burns J., Cogdell R., Dilallo C., Drane L., Estevane E., Ethridge B., Fenn K., Gómez, F., Griffith K., Hrechko B., Hudyncia H., Leblanc T., Lugo C. E., McFather E., Miller G., Oneal C., Suesens J., Tocquigny C., Gulbulak U., Ertas, A.

Boosting Just-in-Time Supply Chain Innovation through Additive Manufacturing: A Transdisciplinary Educational Experience

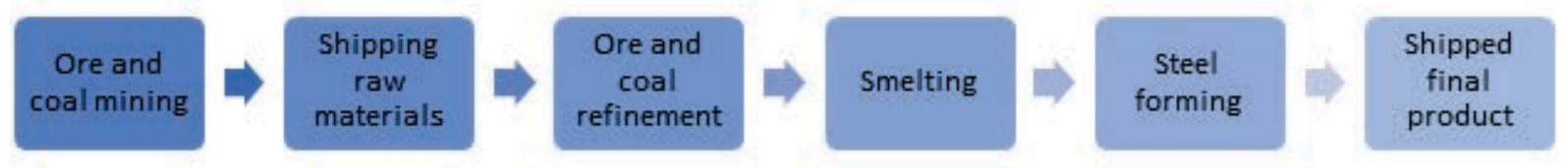

Figure 6: Steel mill supply chain.

Environmental Factors: A major concern within the steel mill industry is the environmental impact. Steel mills must adhere to multiple laws and regulations regarding pollution and emissions in order to continue operations. As time goes on, these laws appear to be getting more and more strict as our society tries to lower its ecological footprint. Since steel is essentially iron with majority of its carbon removed, steel mills' must be careful with the amount of carbon emissions they are releasing. This forces the mills to prioritize minimizing the amount of pollution they are emitting in order to remain up to regulation and running.

Safety Regulations: One of the most obvious critical factors within any company are safety regulations. These regulations are State and Federal guidelines that companies must follow in order to continue operations. The most common government organization imposing these regulations is OSHA (Occupational Safety and Health Administration). OSHA was created to enforce safety and protect employees from almost any hazards. Steel mill employees work with molten metal in extremely high temperatures and are exposed to hazardous materials constantly. A steel mill is constantly at risk to either be shut down for failing to meet safety regulations or to lose valuable employees to injuries or a safer work environment. These reasons alone require safety to be one of the most emphasized factors of a steel mill.

Optimization of Products Variety: For any manufacturing company, their ability to make a variety of different products efficiently directly correlates to their success. The more unique products that are available, the more customers the company will bring in. A steel mill is interested in creating product with different shapes, sizes, and material properties. Customers usually need various types of steel parts in order to meet specific load carrying requirements and ensure their part can function properly. Cur- rently, steel mills are concerned with mass producing steel sheets and billets which are then sent off to a foundry for post processing. If a steel mill can cut out this foundry middleman and sell directly to the consumer, the mill will see a sharp increase in revenue.

Lack of Manufacturing Flexibility: Another critical factor, similar to the optimization of product variety, is the ability to manufacture complex and unique parts. Steel mills focus their attention on making the most basic forms of steel that will eventually be sold and most likely shaped into something of use. Mills are also currently restricted in the processes they use to turn the ore into a steel. Finding different ways to efficiently manufacture steel will allow still mills to become less dependent on meeting specific criterion to process their parts. A steel mills flexibility of manufacturing processes is vital to their success.

Line Stoppage: Line stoppage occurs when a company is forced to halt production due to any internal or external factor. Every manufacturer is focused on minimizing line stoppage in order to continue production and keep the JIT supply chain flowing. Failure to meet safety or environmental regulations are two of the most obvious causes of line stoppage in a steel mill. Other ways this can occur is due to a lack of supplies or an excess of product inventory. If a still mill is not able to have enough raw materials transported in, they are stopped with nothing to do until they get more material. Likewise, if there is not a large enough demand and the mill has an excess of products waiting to be sold, they are forced to stop production.

After team collaboration for collective intelligent (knowledge integration through Extensive literature search and experts opinion), research team decided on the interactions and relationships of the factors affeting steel mill SC as shown in Figure 7. After 
Aldana M., Anselmi P. D. S., Ayala M., Burns J., Cogdell R., Dilallo C., Drane L., Estevane E., Ethridge B., Fenn K., Gómez, F., Griffith K., Hrechko B., Hudyncia H., Leblanc T., Lugo C. E., McFather E., Miller G., Oneal C., Suesens J., Tocquigny C., Gulbulak U., Ertas, A.

Boosting Just-in-Time Supply Chain Innovation through Additive Manufacturing: A Transdisciplinary Educational

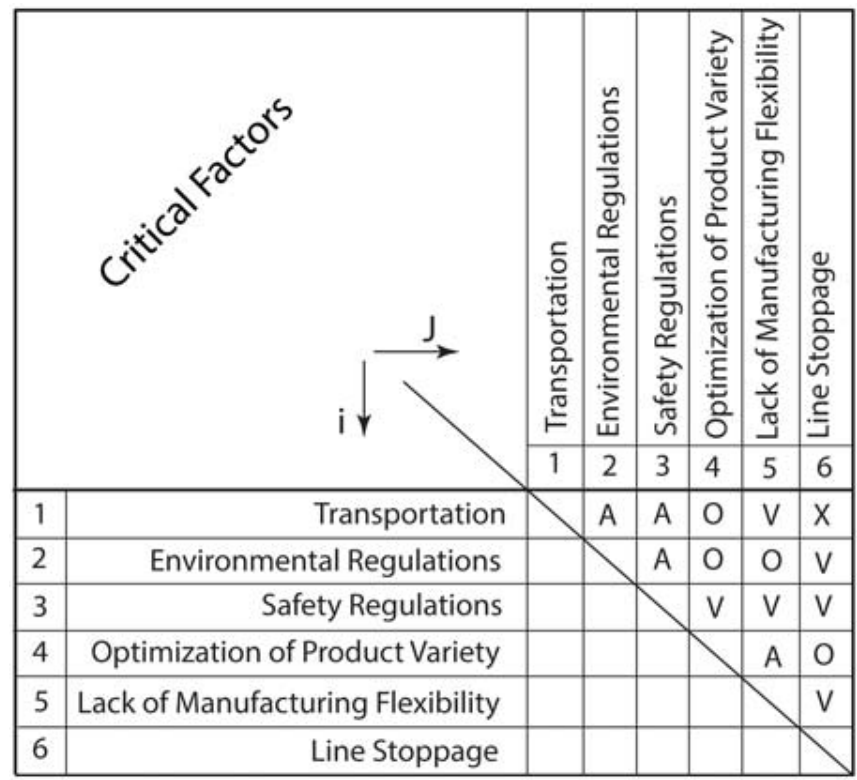

Figure 7: Structural self-interaction matrix.

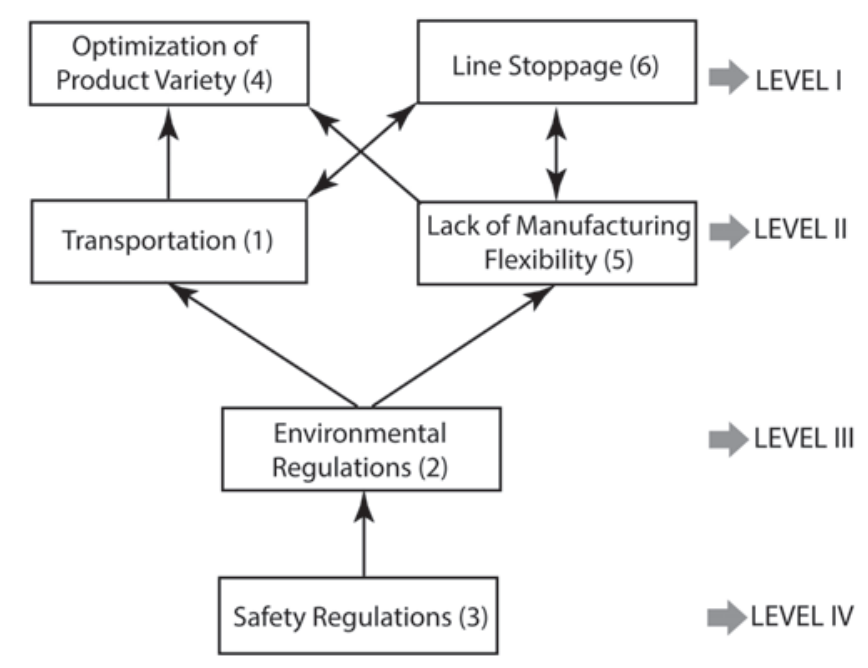

Figure 8: Digraph and ISM levels.

finding the final reachability matrix as described earlier in the ISM approach, the digraph shown in Figure 8 developed. This figure depicts visually the direct and indirect relationships between the factors affecting the performance of JIT steel mill SC. As seen from Figure 8, Safety Regulations (3) is the source factor and the key drivers together with the Environmental Regulation (2). They both have strong driving power but very week dependence (see Figure 9).

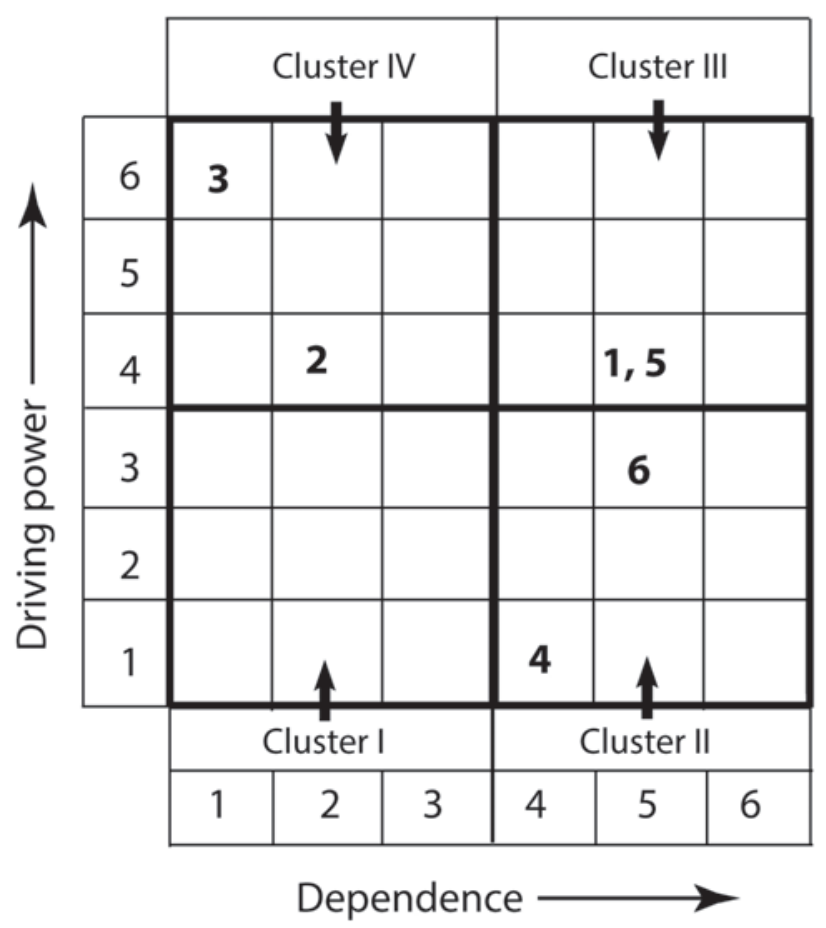

Figure 9: MICMAC diagram.

\subsubsection{Applying Additive Manufacturing for Steel Forming of Supply Chain}

Applying AM for steel forming of SC (see Figure 6) can serve in many avenues for cost reduction and increasing margins. AM provides almost no waste consequently the cost of material can be greatly reduced. A unique advantage to AM is the ability to apply optimized topology to parts. This process removes unneeded material from a part after an finite element (FEA) analysis is applied to the part. Optimized topology creates lighter stronger parts that reduce cost of production and often bear fuel or energy saving qualities [37].

Cost, time, and efficiency are the main driving factors in today's JIT-SC. AM would be a great fit for optimizing all these factors will also increasing the product flexibility inside of steel mills. The current drawbacks of AM revolve around the current limitations restricting its applications. As soon as the technology catches up to the need, AM processes will be almost limitless in their capability to produce products for the growing world's demand.

AM is still a relatively new technology and is constantly changing and advancing. There are many 
Aldana M., Anselmi P. D. S., Ayala M., Burns J., Cogdell R., Dilallo C., Drane L., Estevane E., Ethridge B., Fenn K., Gómez, F., Griffith K., Hrechko B., Hudyncia H., Leblanc T., Lugo C. E., McFather E., Miller G., Oneal C., Suesens J., Tocquigny C., Gulbulak U., Ertas, A.

Boosting Just-in-Time Supply Chain Innovation through Additive Manufacturing: A Transdisciplinary Educational Experience

opportunities in this field to develop new materials and new processes of AM [38]. Having AM within a steel mill allows for many research opportunities. Since the mill produces steel and other alloys, having an AM facility on-site could allow new alloys to be produced and tested within the mill. Creating AM materials on-site can give researchers much higher flexibility since they will not have to outsource the new material's production. Additionally, researchers can rapidly change the composition of alloys to adjust material properties to optimize AM qualities.

\subsection{Case Study-III: Additive Manufacturing \& Supply Chain Driven Prosthesis}

Student Research Team: Blaze Ethridge, Kyle Griffith, Hans Hudyncia, Garrett Miller and James Suesens

For medical prosthetics, material selection is an important aspect: from simulating weight similarities, dexterity, and material strength-having a prosthetic limb simulate the natural limb is relatively difficult. With 3D printing many patient specific improvements and selections can be made. From material selection, aesthetics and functionality can be made more quickly and accurately compared to simple molding and forming of the prosthetic.

Many different prosthetics are typically made from plastics, the main component of medical devices is biocompatibility and their ability to simulate natural organs. With conventional prosthetic limbs, the forming of plaster casts with a custom fitted socket is the usual standard for most arm prosthesis. With the weight being a main concern, and the artificial limb being made of plastics, it becomes difficult to produce a limb with functionality. To keep weight down and add function to the hands or limbs, some exotic materials such as aluminum and titanium are used to keep the strength of the prosthetic high while reducing weight constraints.

With conventional measuring and casting, the lengths of the body are measured, and relevant sections of the body are referenced to make the cast. Using impression casting, a plaster cast of the patient's stump is made so that the fitting is as close to natural as possible. Then from the cast, a positive model is created, and a duplicate can be used to create the new prosthetic limb. This process can be long and take between two to three weeks for

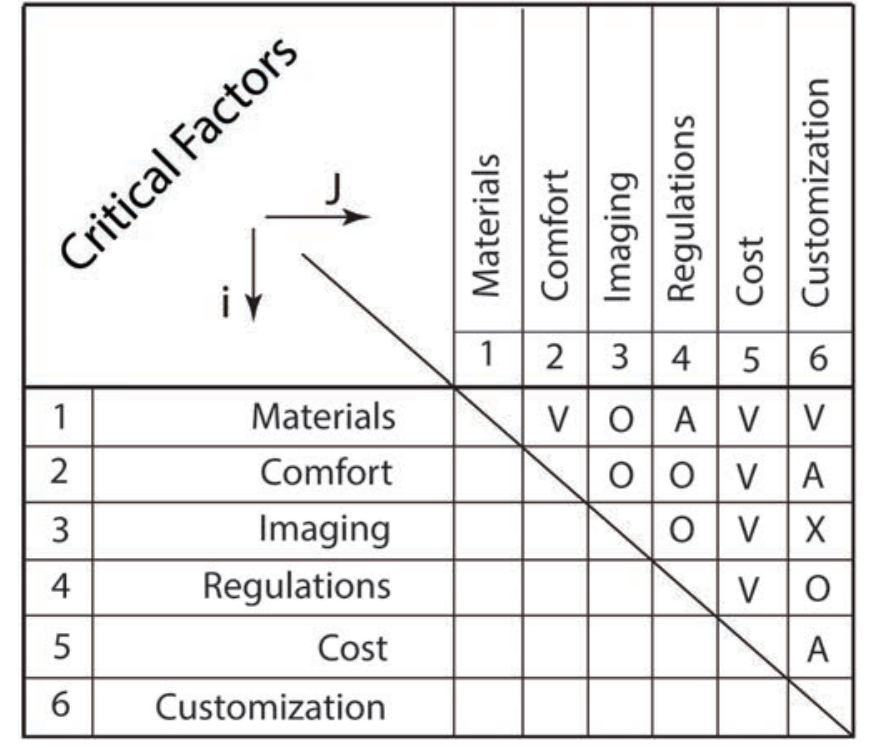

Figure 10: Structural self-interaction matrix.

production of an accurate product [39].

Making the socket is a very important aspect for comfort and longevity of the prosthetic. A sheet of thermoplastic is vacuum formed around the mold. Next the permanent sock is made and tested repeatedly on the patient to ensure it is comfortable and not loose on the body. Lastly, the prosthetic limb is fabricated. Plastics like polypropylene, polyethylene, acrylics, and polyurethane are used for the limb and this is done by injection molding or forced molding and extrusion, while foams and liners are the used as the materials for the socket [40]. The final processing involves a technician assembling the prosthetic with screws and bolts and the final adjustments of the limb are made with the patient.

\subsubsection{Additive Manufacturing \& Supply Chain Driven Prosthesis ISM Analysis}

Extensive literature-based research was performed by the research team to develop a full sense of understanding of the following each individual factor to create the SSIM Matrix shown in Figure 10. This SSIM is developed to build comprehension of which factors will affect one another.

Cost: JIT manufacturing techniques have desirable financial benefits for any given industry, especially in the growing prosthetics department of the medical industry. Warehouse space and any physical 
Aldana M., Anselmi P. D. S., Ayala M., Burns J., Cogdell R., Dilallo C., Drane L., Estevane E., Ethridge B., Fenn K., Gómez, F., Griffith K., Hrechko B., Hudyncia H., Leblanc T., Lugo C. E., McFather E., Miller G., Oneal C., Suesens J., Tocquigny C., Gulbulak U., Ertas, A.

Boosting Just-in-Time Supply Chain Innovation through Additive Manufacturing: A Transdisciplinary Educational Experience

real estate consume a large percentage of a manufacturing budget. The idea of only holding on to physical material as demand for product grows allows for an overall reduction in physical warehouse space. This reduction in physical space and on hand materials allows for considerable cost reduction in the business model.

$\mathrm{AM}$ has the unique capability to reduce the amount of capital normally necessary to increase the speed and profitability of production. Specialty components or parts that are commonly used in the build process can be printed in batches opposed to the methods of traditional manufacturing. It is incredibly easy to change or revise versions of any product. This is one of the largest benefits of utilizing AM technology for oprosthetic hands as many deformities are especially unique and many require multiple fittings and adjustments. Subtractive manufacturing techniques are at risk of producing an improperly fitting prosthetic that must be discarded and replaced whereas AM grants a degree of leeway. This key benefit drives the financial stability of the business plan. The ability to print complex inner geometric fills allows for parts to be lightweight in nature. Not only does this geometric fill option increase performance, it also allows for material savings and consequentially cost savings.

Materials: Using 3D extrusion, material selection can be expansive and patient specific. Polymers are the main material in use due to their lightweight characteristics, profitability and affordability while also being biocompatible. Creating the forearm out of an exoskeleton of polymers such as nylon, polycarbonates, or polycarbonate-ABS composite gives great mechanical properties at the limit of the attachment point to the body as well as reducing material and cost. With the forearm designed as a hollow exoskeleton, the electromechanical components can then be stored in the forearm to allow for the articulation of the hand, much like that of a natural hand.

The main advantage to our 3D printing capability is the ability to create composite prosthetics easily; with direct metal laser sintering (DMLS), prints of titanium or stainless steels can be used in the hand and mounted to the polymer forearm easily; this allows for precise articulation of the wrist and fingers while also maintaining realistic form factor and mechanical properties of a natural hand. In comparison, with existing casting of prosthetics, only top tier prosthetics have articulation of the hand and the average prothesis has no articulation due to machining complexities and cost. Another advantage to the DMLS process is the ability to be patient specific and design hands to the correct proportions of the patient while also maintaining the ability to produce large quantities for multiple patients with each print.

Imaging: Currently the process to make a prosthetic custom fitted to a limb involves using different molding techniques to create the shape of the injured limb and then custom building the prosthetic to fit the limb mold. This requires that the limb be completely healed so there is no swelling and it can still take days or even weeks to go through the whole casting process to get to the finished prosthetic. AM techniques can come into play and drastically help to reduce that time frame. Imaging techniques like computed tomography (CT) Scans can be used to generate 3D models of the injured limb and can then be used to generate a personal prosthetic shaped perfectly for the patient.

Imaging influences the JIT-SC by drastically reducing the amount of stock necessary for the casting material. Imaging also increases the accuracy of our prosthetics by reducing human error of each step, giving each patient a more custom fit solution. The JIT-SC pivots on fast production of parts and there is no faster way than scanning an arm injury and immediately generating a perfectly fit to patient prosthetic limb. Where the current process can take weeks, a scan and print can be done in the same day allowing the patient to use their new prosthetic sooner.

Regulations: Environmental factors are closely tied to the regulations by law. By reducing environmental impact, regulations may come into place, eliminating more wasteful methods of production. The JIT aspects of creating prosthetics allows end use products to be developed in a relative short time with less material, consequently create less of a carbon footprint and allows us to be more environmentally friendly.

Comfort: Limbs may take time to fit into the shape of prosthetics. Hence, the patient may experience discomfort if the prosthetic is not designed to 
Aldana M., Anselmi P. D. S., Ayala M., Burns J., Cogdell R., Dilallo C., Drane L., Estevane E., Ethridge B., Fenn K., Gómez, F., Griffith K., Hrechko B., Hudyncia H., Leblanc T., Lugo C. E., McFather E., Miller G., Oneal C., Suesens J., Tocquigny C., Gulbulak U., Ertas, A.

Boosting Just-in-Time Supply Chain Innovation through Additive Manufacturing: A Transdisciplinary Educational Experience

the best size and need of the patient. With the help of imaging and AM this discomfort can be eliminated drastically.

Customization: The customization and fit of the prosthetic are heavily dependent on the materials used, the accuracy of the imaging and reconstructive technologies, and the process used to make the part. Because limb prosthetics are primarily noninvasive, a relatively large variety of materials can be used. The process used to make the part is important because it must be accurate, but not all parts will be the same. Therefore, AM is perfect for this application.

Through ISM approach, research team developed Digraph and MICMAC diagram shown in Figures 11 and 12, respectively. As shown in Figures 11 and 12 imaging is affected by almost other factors except cost. It is in the Cluster III (dependent) MICMAC diagram. Cost (5) is affected by all the other factors. Cluster IV includes independent factors of Regulation (4) and Materials (1) with a strong driving power but very weak dependence. These two factors are the key drivers. Regulation (4) is the source factor since it has only outgoing path.

The application of AM in patient specific prosthetics is an excellent replacement for the conventional manufacturing processes with molding and vacuum forming. By increasing the accuracy of the prosthetic design with the addition of the layered imaging from $\mathrm{CT}$ scans, the prosthetics will require less post processing and fitting for the patient. AM also improves the material selection, biocompatibility, customizability, while reducing the cost. The addition of AM establishes a JIT to the existing industry, by reducing fitting time and manufacturing time, the patient can receive their prosthetic faster than ever. Through this process, product defects can also be minimized considerably.

\subsection{Case Study IV: Supply Chain Analysis of Toyota}

Student Research Team: Benjamin Hrechko, Taylor LeBlanc, Christopher O'Neal, Christian Dilallo Luke Drane

The Toyota Corporation first started including JIT manufacturing as part of their process as far back as 1952, and had it fully implemented within a

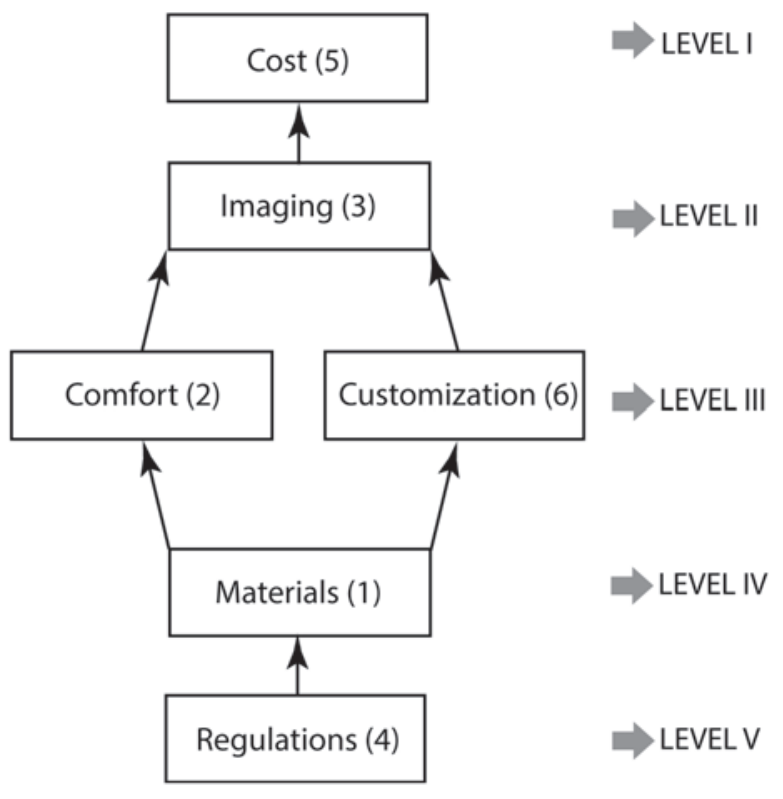

Figure 11: Digraph.

decade. Since then it has streamlined and perfected the JIT-SC in all their factories across the world. Their methodology utilizes all the current and most efficient manufacturing methods. However, the one side of manufacturing that they have not utilized on a large scale is that of AM. AM has the potential to help speed up and save money with certain aspects of the entire manufacturing process for Toyota. One potential use involves removing the need for produce certain parts offsite through other companies, instead printing them in house using multiple printers. This would save money in transportation, material cost, and the need for multiple injection-mold machine operators. Although AM will not be applicable to every process, it has the potential to be the next great step in JIT manufacturing.

Since its inception, the Toyota Motor Company has been a shining example of how to successfully build, manage, and maintain a JIT-SC in their production of high-quality motor vehicles. Similarly, $\mathrm{AM}$ is continuing to make strides in improving its production speed and product fidelity. Due to the nature of AM it is unsurprising that many companies are investigating the viability of using such techniques in their manufacturing processes to further streamline their SC. There are however some factors in their $\mathrm{SC}$ to consider when discussing the possibility of changing it to such a degree. As such, the factors involved in managing Toyota's SC will 
Aldana M., Anselmi P. D. S., Ayala M., Burns J., Cogdell R., Dilallo C., Drane L., Estevane E., Ethridge B., Fenn K., Gómez, F., Griffith K., Hrechko B., Hudyncia H., Leblanc T., Lugo C. E., McFather E., Miller G., Oneal C., Suesens J., Tocquigny C., Gulbulak U., Ertas, A.

Boosting Just-in-Time Supply Chain Innovation through Additive Manufacturing: A Transdisciplinary Educational Experience

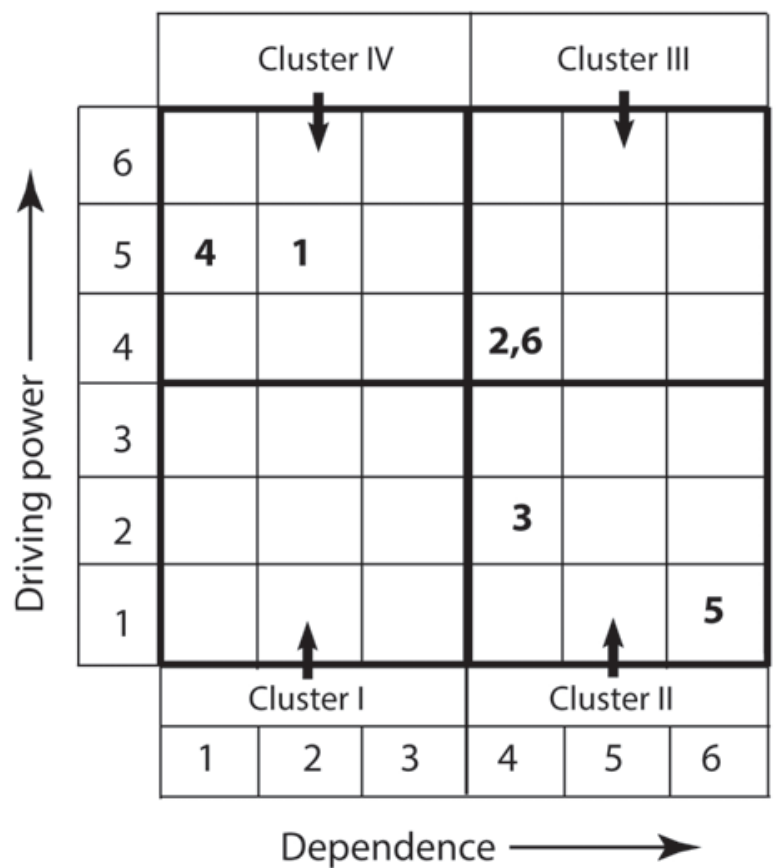

Figure 12: MICMAC Analysis.

be assessed, as well as the viability of incorporating AM techniques in their SC using their San Antonio manufacturing plant as an example.

\section{Toyota's Supply Chain at San Antonio Manufacturing Plant:}

There are many uses for AM, not just for Toyota, but the entire vehicle industry in general. One method that Toyota is currently in the early stages of is implementation of AM for their 2019 Avalon headlights. This method is a test run for Toyota in order to see if the technology has advanced enough to be implemented in other areas of the manufacturing processes. Initially, AM was only used to produce cheap, quick, and effective prototypes for testing different designs, but now Toyota is looking at using it to further optimize their supply chain Their current method for producing their headlights is Plastic Injection Molding (PIM). There are 2 areas that AM currently struggles to compete with PIM, the scale/quantity of products being produced and the quality that those parts have.

When looking at AM to replace PIM, AM must save Toyota money and it also needs to keep the model of JIT if not improve it. Toyota's current production of headlights allows them to keep up with their output of one car every 50 seconds. To keep up with this production every 30 seconds a headlight is produced and it takes 2 hours for printing [41]. Under the assumptions of an 8 hours shift for the PIM operators and a 22 hours runtime for the printers, Toyota would need a minimum of 88 printers to match the output of the PIM. Their facilities would either have dozens of printers or they would need to keep a stockpile of inventory.

While PIM is a high labor process with little skill needed, AM only requires a technician to set up the printers. But due to AM being in its beginning stages it requires skilled personnel to inspect and do post-processes of the parts. Another aspect is for every new design of headlight the initial investment of $\$ 400,000$ is needed for the cost of tooling which would be eliminated by using AM. The initial investment would be negligible on high volume but would be high on specialty parts. Parts are required to be supplied for around 15 years after the vehicle goes out of production. Over that time production is at $1-2 \%$, but during this time they must pay for the upkeep of the tooling and any equipment need for the process. This problem grows exponentially as vehicles become more customizable, and new models come out. Which leads to factories needing more floor space to fit the machinery to produce the various parts. Currently it takes 30 different PIM parts to create one headlight, Figure 13 shows how much floor space is needed to store the tooling to create a headlight. This does not include the needed space for storing the old tooling for the last 15 years of cars; AM eliminates these problems. Another issue that factories run into with plastic injection molding is when a mold needs to be changed, due to issues in the final part, the mold must be fixed by a skilled shop that is very costly that also take up to six weeks to finish.

With the release of their new vehicle, the "i-Road super-compact electric vehicle", they are allowing for a new form of customization and personalization with interchangeable panels that can be produced with AM processes form household printers (see Figure 14). There is already a larger and strong set of people who are dedicated to the personalization of their car with tire, rim, body parts, etc. and this application reaches out to those hobbyists and people who interested in 3D-printing. Another way Toyota can use this application to generate more profit by selling their own interchangeable parts as an option for customers to purchase [42]. 
Aldana M., Anselmi P. D. S., Ayala M., Burns J., Cogdell R., Dilallo C., Drane L., Estevane E., Ethridge B., Fenn K., Gómez, F., Griffith K., Hrechko B., Hudyncia H., Leblanc T., Lugo C. E., McFather E., Miller G., Oneal C., Suesens J., Tocquigny C., Gulbulak U., Ertas, A.

Boosting Just-in-Time Supply Chain Innovation through Additive Manufacturing: A Transdisciplinary Educational Experience

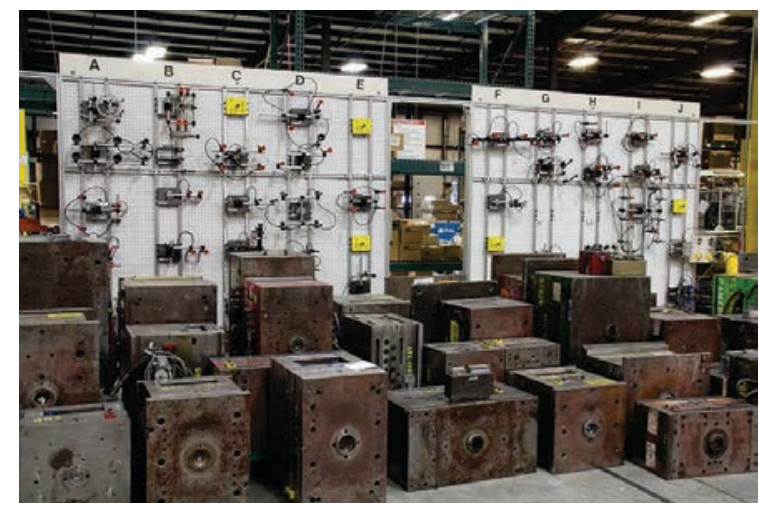

Figure 13: Tooling for plastic injection molding [31].

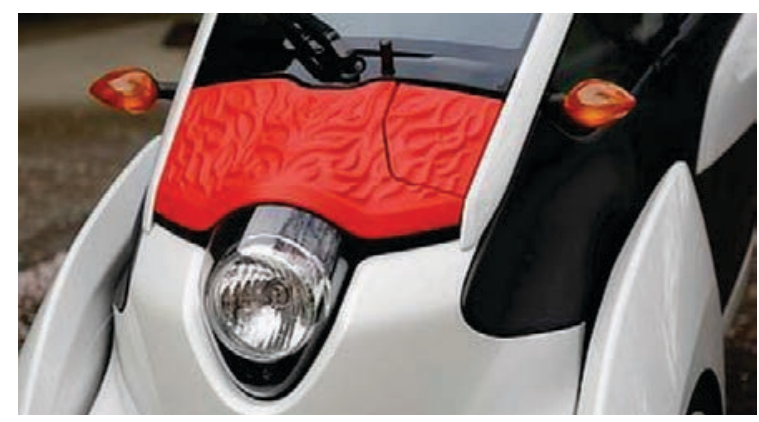

Figure 14: The i-Road Super-Compact Electric Vehicle [32].

\subsubsection{Toyota Supply Chain ISM Analysis}

The ISM method was used with the concept of the Toyota supply chain for a better understanding of additive manufacturing's role in the future of the company. As shown in Figure 15 following six supply chain factors were identified based on the project goal and desires.

Supplier Constraints: The raw materials supplied by another company outside of Toyota or manufactured parts used in the production of individual cars. There is an understanding that the supplier will have the parts or materials on time, every time.

Demand Fluctuation: The change in demand of customers for a manufactured vehicle over a specified period of time.

Cost: The cost associated with creating the average car out of the Toyota manufacturing plant in San Antonio, Texas.

Product Optimization: The process optimization of the plant in an effort to reduce waste and increase efficiency.
Logistics: The process of supplying products to the customers and raw materials or small parts to the manufacturer.

MICMAC analysis of this part of the research where each factor is categorized and then lumped in a cluster is shown in Figure 16. The relationship between each factor is also shown in Figure 17.

As shown in Figure 17 above, the most important driving factor for Toyota's supply chain is the supplier constraints (7). This makes sense given that Toyota is a JIT-SC pioneer and requires not only good relationships with their suppliers but also needs very dependable suppliers to get their material on time and in the correct amount every single time. While researching JIT-SC for this paper, a trend emerged that every company who employs this type of SC has reliable and big-name suppliers for the basic needs of their company.

The second most important factor according to the digraph in Figure 17 is the quality control of the manufactured product. Without a solid design and quality control division within the manufacturing plant the customers will complain to a customer 
Aldana M., Anselmi P. D. S., Ayala M., Burns J., Cogdell R., Dilallo C., Drane L., Estevane E., Ethridge B., Fenn K., Gómez, F., Griffith K., Hrechko B., Hudyncia H., Leblanc T., Lugo C. E., McFather E., Miller G., Oneal C., Suesens J., Tocquigny C., Gulbulak U., Ertas, A.

Boosting Just-in-Time Supply Chain Innovation through Additive Manufacturing: A Transdisciplinary Educational

\begin{tabular}{|c|c|c|c|c|c|c|c|}
\hline \multirow{2}{*}{\multicolumn{2}{|c|}{$i \downarrow$}} & 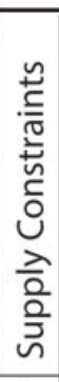 & 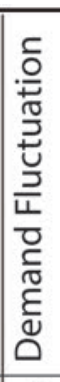 & 苍 & 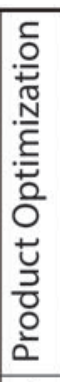 & 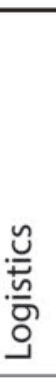 & 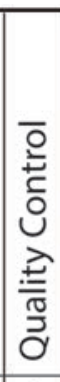 \\
\hline & & 1 & 2 & 3 & 4 & 5 & 6 \\
\hline 1 & Supply Constraints & 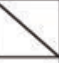 & 0 & V & V & $x$ & V \\
\hline 2 & Demand Fluctuation & & 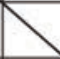 & $x$ & $x$ & V & $A$ \\
\hline 3 & Cost & & & 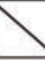 & $x$ & A & A \\
\hline 4 & Product Optimization & & & & 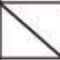 & $\mathrm{O}$ & A \\
\hline 5 & Logistics & & & & & & 0 \\
\hline 6 & Quality Control & & & & & & \\
\hline
\end{tabular}

Figure 15: SSIM of Toyota supply chain.

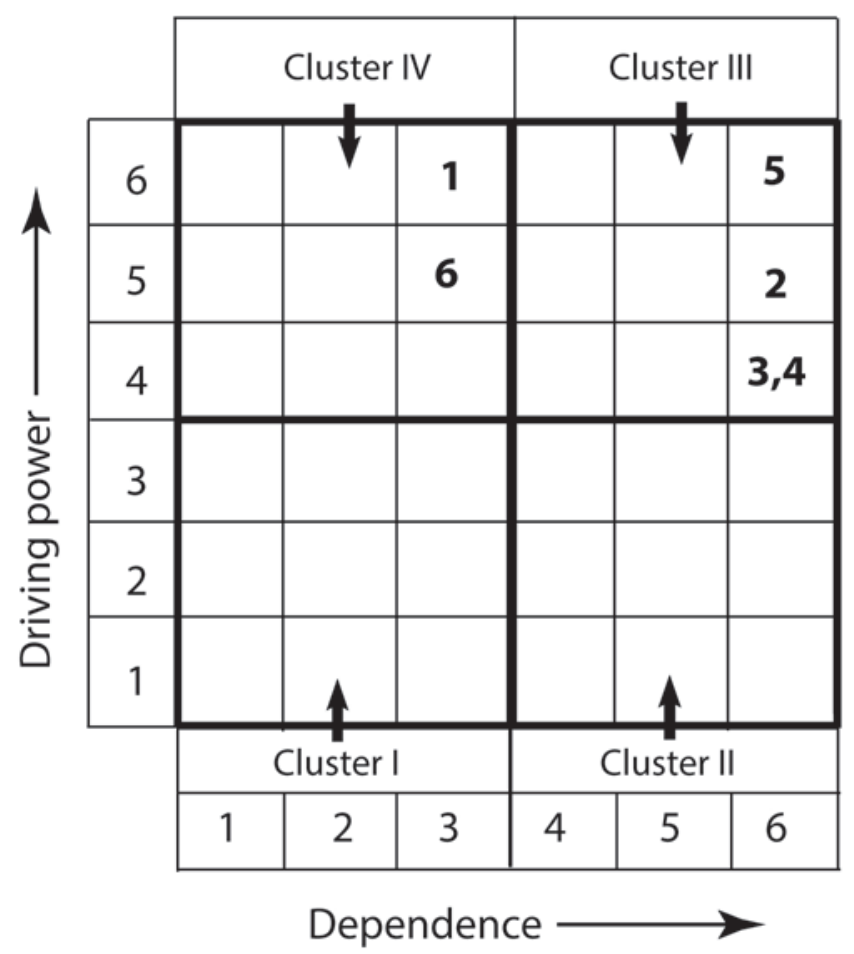

Figure 16: MICMAC analysis.

service representative hurting both profits as well as word of mouth advertising.

The least important of the six factors are shown at the top level of Figure 17. While these might not make or break the supply chain, they are important cogs in the process and help to create a baseline that the company uses to run efficiently and effectively.
These factors also show up in the "linkage" cluster in the MICMAC (see Figure 16) meaning that changing one will have a profound effect on the other three and change the SC as a whole, for better or for worse.

\subsection{Case Study V: Supply Chain Analysis of Honda}

Student Research Team: Erik Estevane, Kyle Fenn, Dylan Anselmi and Mario Aldana

Honda Motor Company sells millions of products every year, ranging from cars to motorcycles to various power tools. The focus of this study will be on Honda's car manufacturing SC, how AM is currently being used, and how AM can be further implemented. AM is a relatively new manufacturing technique. While 3D printing itself has been around for decades, it has only been recently adopted by large scale manufacturers as a viable manufacturing method. One of these manufacturers is Honda Motor Company. Honda uses the just-in-time manufacturing model. Originally pioneered by Toyota, JIT manufacturing has become a popular manufacturing model amongst other automakers. One of the core principles of JIT manufacturing is the arrival of parts for assembly only as needed. The inherent nature of AM means that parts can be made to order without having to worry about other logistics such as delivery schedules from suppliers. Thus, Honda stands to greatly benefit from AM technology.

As competition in the auto industry grows fiercer, with 88 million autos being sold worldwide in 2016, car manufacturers are constantly trying to improve processes by testing new technology to gain an edge. AM is leading these product development enhancements by allowing companies to create cars that are lighter, more attractive, and safer, all while having shorter lead times.

Honda, besides of integrating the uses of AM on the production line, they are beginning to take a step further with these processes. Particularly in China where Honda is a status symbol, by using $3 \mathrm{D}$ printing to customize car parts, it opens new possibilities for consumers who want their car to be different from the crowd. The use of AM is reducing scientifically the lead times to get custom vehicles while enhancing their satisfaction with the product by delivering exactly what they want in a car.

With all the competition that is going on today 
Aldana M., Anselmi P. D. S., Ayala M., Burns J., Cogdell R., Dilallo C., Drane L., Estevane E., Ethridge B., Fenn K., Gómez, F., Griffith K., Hrechko B., Hudyncia H., Leblanc T., Lugo C. E., McFather E., Miller G., Oneal C., Suesens J., Tocquigny C., Gulbulak U., Ertas, A.

Boosting Just-in-Time Supply Chain Innovation through Additive Manufacturing: A Transdisciplinary Educational Experience

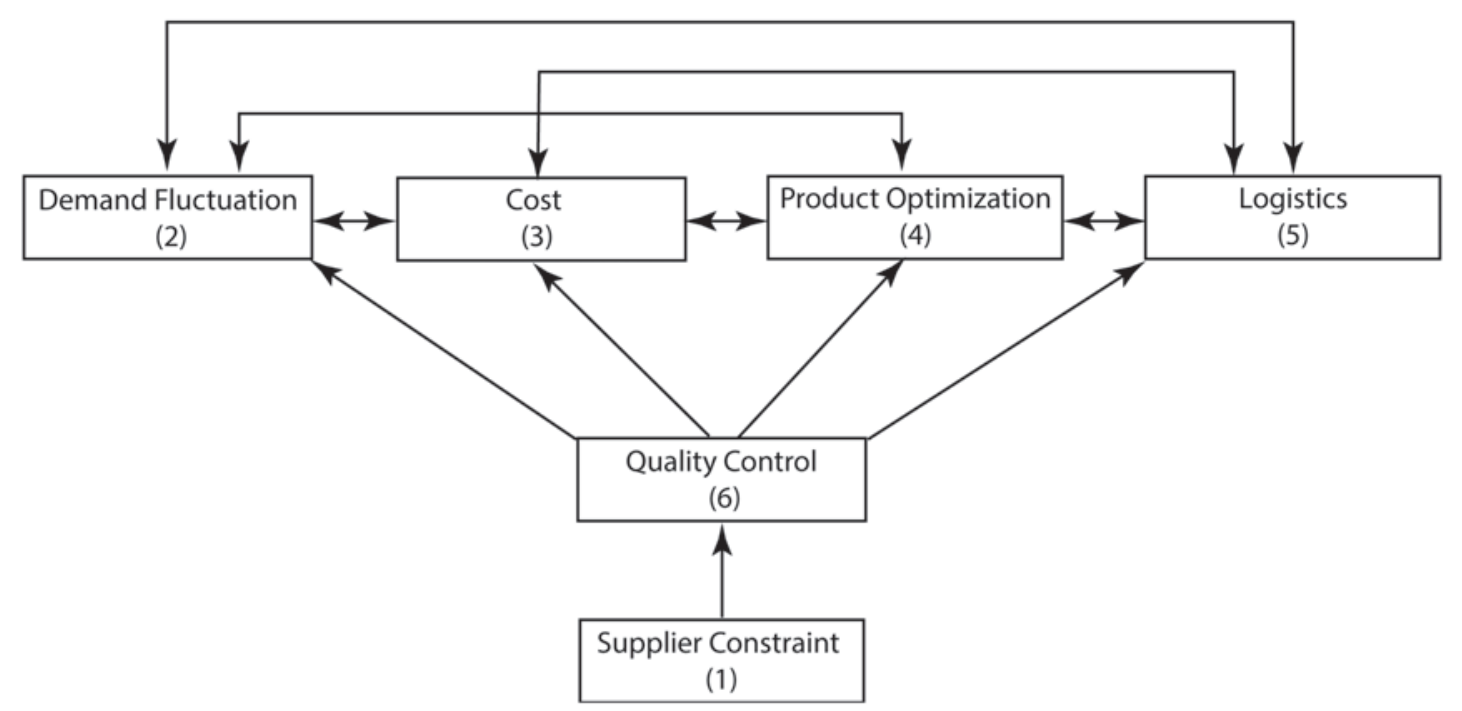

Figure 17: Digraph.

there is an imminent need for developing new technologies not only to stay ahead of the business but also to improve the way company can incorporate a more sufficient and advance supply chain.

AM can make Honda less dependent on suppliers. As it stands, if there is an issue with any supplier, production can be ground to a halt. With AM, Honda can make parts that were previously sourced from suppliers. Provided the AM machines are operating correctly, this allows Honda to have a more consistent production schedule. Additionally, since the AM will be done in house, Honda can save money in the long run since they no longer need suppliers for the parts that will are produced from AM.

Honda initially started its operations as a motorbike producer, it was one of the biggest manufacturers of Japan following WW2. Because of the success that they had with this implementation they began the productions of cars in 1963, Honda vehicles reached all over the world in a short amount of time. Following steps of other giants such as Toyota, implementing new technics such as JIT-SC, and going forward new manufacturing process including AM [43]. All of this have been included to this SC to make Honda one of the biggest car manufacturers of the world.

\subsubsection{Overview of Honda's Supply Chain}

SC management function of Honda is working at its best by integrating all the departments and properly dividing all the tasks among them. Role of different employees along with their supervising authorities have been defined that helps in making better flow of work and increased productivity. The overall supply chain management of Honda works through the following process:

Buying Policy: For the reason of recognized global nature of buying utility, Honda has industrialized and utilizes a simple buying strategy that can be labeled by means of the following belief that "Honda will purchase from the maximum modest dealers in demand to achieve client gratification." [43]

Supply: Stable supply of better products and services is necessary to put significant effort into developing and optimizing supply chains with suppliers around the world while also taking into account environmental and human rights issues [39]. Honda, which is a broad-based industry supported by many suppliers, must pursue the reduction of not only their own environmental impacts but also those of suppliers throughout their entire supply chain.

Quality: Quality is utmost significant feature in safeguarding client gratification. Honda considers that the excellence needs to be constructed into the creation all through manufacturing procedure. It is the accountability of all dealers and every discrete employee to safeguard superiority.

Cost: Rivalry in the parts supply business has turn out to be actually solid in current ages. Honda is 
Aldana M., Anselmi P. D. S., Ayala M., Burns J., Cogdell R., Dilallo C., Drane L., Estevane E., Ethridge B., Fenn K., Gómez, F., Griffith K., Hrechko B., Hudyncia H., Leblanc T., Lugo C. E., McFather E., Miller G., Oneal C., Suesens J., Tocquigny C., Gulbulak U., Ertas, A.

Boosting Just-in-Time Supply Chain Innovation through Additive Manufacturing: A Transdisciplinary Educational Experience

dogged to deliver yields at modest values and worth for the currency. Dealers are probable to attain marks, price to attain their thoughts, machineries, enhanced output plus combined work with Honda in value manufacturing or value exploration doings [38] Honda needs dealers' incessant labors to decrease rate time to time. Honda will provide the dealers yearly rating for their raw substantial so that they are capable to adjust the rate of every amounts which drives into diverse model vehicles.

Delivery: Honda works on JIT making scheme. In order to reply rapidly for the client's request, it is attracting more and more acute to yield merchandises with the undeviating likely lead times [44]. Just in time decreases portfolio, remove leftover, and likewise recovers manufacturing effectiveness. Implementing just in time slender manufacturing will increase dealers' keenness in rate and excellence.

Management: It is vital for a dealers' managing group to be powerfully customer oriented and to offer real management for the whole business [43]. Such organization exertion endorses joint faith among the dealer and Honda.

Disposal: Vehicles and part that have already completed their lifespan have been utilized in different parts of productions such as testing, recycling and other processes where the use of raw material can by implied.

\subsubsection{Just in Time Manufacturing}

For decades, Honda has used JIT Manufacturing in their manufacturing plants. To do this, Honda cooperates with independent suppliers for parts used in their vehicles. These independent suppliers supply parts such as loudspeakers, seats, and many other parts. Most of these suppliers deliver to one of Honda's manufacturing plants up to three times a day. Once these parts are delivered, parts are transported directly to the assembly line and installed on the vehicles immediately [45]. Using this JIT approach, Honda avoids getting stuck with outdated inventory by eliminating their need for storage in the first place. Other advantages of JIT manufacturing include a reduced risk of damaged parts, and ultimately a more efficient production operation.

\subsubsection{Additive Manufacturing}

Currently, Honda is pursuing AM as a way to for potential customers to further customize the interiors of limited-edition vehicles [46]. Parts usually must be designed with traditional manufacturing techniques in mind. This limits the range of parts that a manufacturer can make. AM can manufacture parts with different geometries without requiring any change of tooling. This aspect of AM saves both time and cost. Normally, there are only a limited amount of interior options and trims available to the customer for any given vehicle. Since AM can build a diverse amount of parts, it can allow Honda to greatly expand the amount options to a customer. Honda can have the ability to tailor each separate vehicle to a specific customer's needs.

The potential of AM expands even further than having custom vehicles. Currently, many auto manufacturers are using AM to streamline the prototyping process. This leads to quicker development times and as a result, can save in design costs. Additionally, there has been a push for additive manufacturing to create parts that are more structural in nature. This endeavor has the potential to reshape the entire logistical chain. Parts that were originally dependent on suppliers can now be made in house.

\subsubsection{Honda Supply Chain ISM Analysis}

Honda's JIT-SC has many factors that affect its efficiency in many ways. The research team carefully analyzed the SC and selected six main factors that affect the SC at the macro level: Supplier, Part Prototyping, Demand, Transportation, Machine Downtime, Laws \& Regulations.

The first main factor are the suppliers of raw material and outsourced parts. Since Honda does not have large warehouses to store parts and materials, it is highly depended on suppliers to deliver their products on time to prevent a slowdown. Part prototyping is the process of using AM machines to accelerate the prototyping process of designing and improving parts as opposed to using traditional machining processes. Another factor is market demand, which can easily change depending on the economy and human behavior. Honda must do its best to meet this demand as quickly and efficiently as possible. Transportation deals with delivering Honda's products to global dealerships by means of using 
Aldana M., Anselmi P. D. S., Ayala M., Burns J., Cogdell R., Dilallo C., Drane L., Estevane E., Ethridge B., Fenn K., Gómez, F., Griffith K., Hrechko B., Hudyncia H., Leblanc T., Lugo C. E., McFather E., Miller G., Oneal C., Suesens J., Tocquigny C., Gulbulak U., Ertas, A.

Boosting Just-in-Time Supply Chain Innovation through Additive Manufacturing: A Transdisciplinary Educational Experience

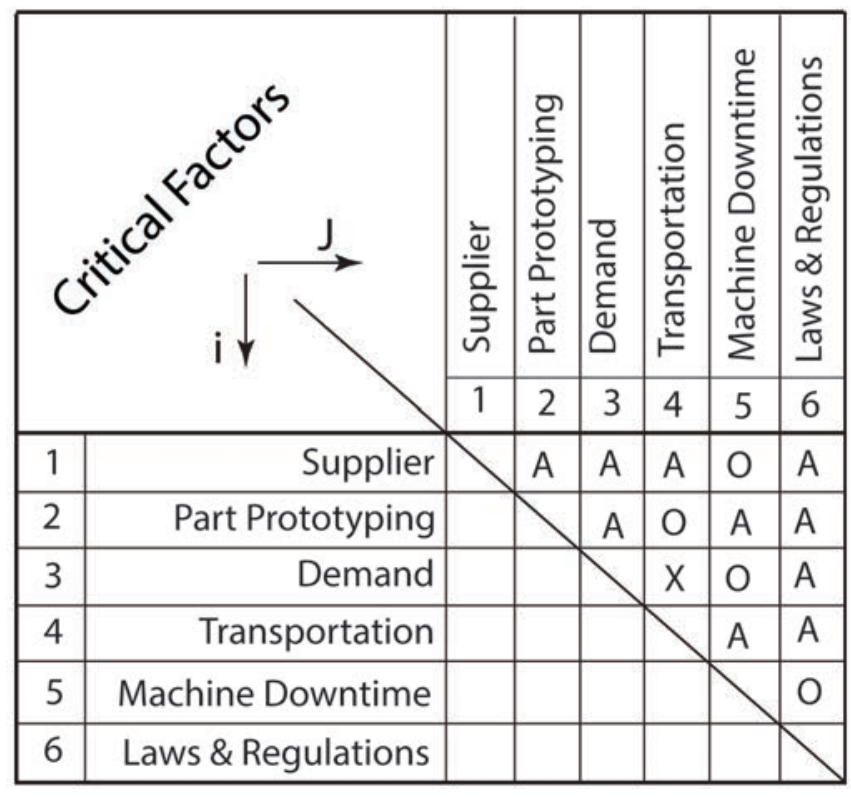

Figure 18: SSIM of Honda supply chain.

trucks, trains, and ships. These must be on time to prevent Honda from stockpiling their products in their assembly plant. Machine downtime is the effect of manufacturing and assembly machines breaking down, which can sometimes bring production to a halt, and affecting all other factors. Laws and regulations are different for every country so Honda must abide by the local laws to get their product on the market.

Using the factors mentioned above, a SSIM matrix (Figure 18) was created to display the relationship between the factors and how they affect each other Using final reachability matrix relationship network (Figure 19) and MICMAC analysis chart (Figure 20) were created.

The MICMAC analysis chart shows the dependence and driving power of each of the factors affecting the JIT-SC of Honda. Machine downtime (5) and laws \& regulations (6) were shown to be the factors with the highest driving power. Machine downtime greatly affects other factors since it can bring production to a halt if an assembly machine were to break down. Suppliers and final product transportation would need to slow down or stop the delivery of products to the assembly plant or dealerships. Honda would also not be able to keep up with a sudden product demand (3) and part prototyping (2) would need to slow down if the machine was a 3D printer. Laws \& regulations (6) are different for every country and they may change at any time so when they do, Honda must adjust their supply chain to accommodate it. If there are new tariffs imposed, transportation (4) will be affected. Higher taxes on cars may also lower the demand which would slow down production. Regulations on 3D printed parts would put specific constraints on the materials and processes allowed.

Demand (3) and transportation (4) are factors with medium driving power and medium dependence on other factors. Demand can sometimes be unpredictable as it can change due to the economy or people's interest on the product. If there is too little or too much demand, transportation will be affected as there can be a lack or excess of transportation vehicles. Part prototyping (2) will be affected if there is too much demand, as all the machines would be used to make production parts. Transportation (4) will also affect part prototyping indirectly if it is affected by machine downtime or laws \& regulations. Supplier (1) and part prototyping (2) are the factors with the highest dependence on other factors and low driving power. Suppliers (1) are affected if production slows down since they would have to also sell less products. Also, if Honda stops outsourcing prototype parts, suppliers would lose business.

Honda Motor Company is a key player in the design and manufacturing of vehicles, motorcycles, and power tools. Honda has perfected their JIT Manufacturing approach. For decades, Honda has used theirJIT Manufacturing approach to save storage needs and create a more efficient production operation. Currently, Honda is using AM in their manufacturing facilities by having customers customize the interior of their vehicles, but Honda plans to do much more with this technology. Based on the ISM, part prototyping using AM is affected by the production and efficiency of the assembly plant. In the future, Honda plans to use AM to streamline their design and prototyping process, ultimately saving Honda time and money. Honda also plans to use the technology to build stronger and cheaper parts in house.

\section{JIT Supply Chain Complexity Metric}

Cyclomatic complexity is a metric used to measure complexity of a process, developed by Thomas J. 
Aldana M., Anselmi P. D. S., Ayala M., Burns J., Cogdell R., Dilallo C., Drane L., Estevane E., Ethridge B., Fenn K., Gómez, F., Griffith K., Hrechko B., Hudyncia H., Leblanc T., Lugo C. E., McFather E., Miller G., Oneal C., Suesens J., Tocquigny C., Gulbulak U., Ertas, A.

Boosting Just-in-Time Supply Chain Innovation through Additive Manufacturing: A Transdisciplinary Educational Experience

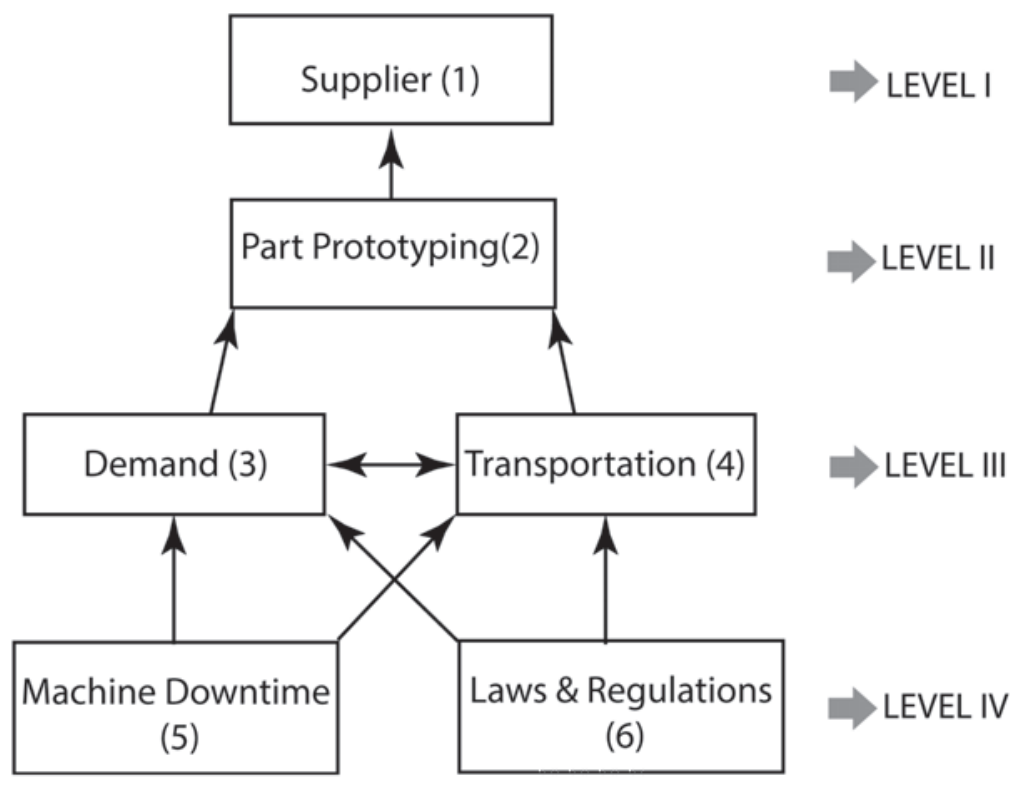

Figure 19: Digraph.

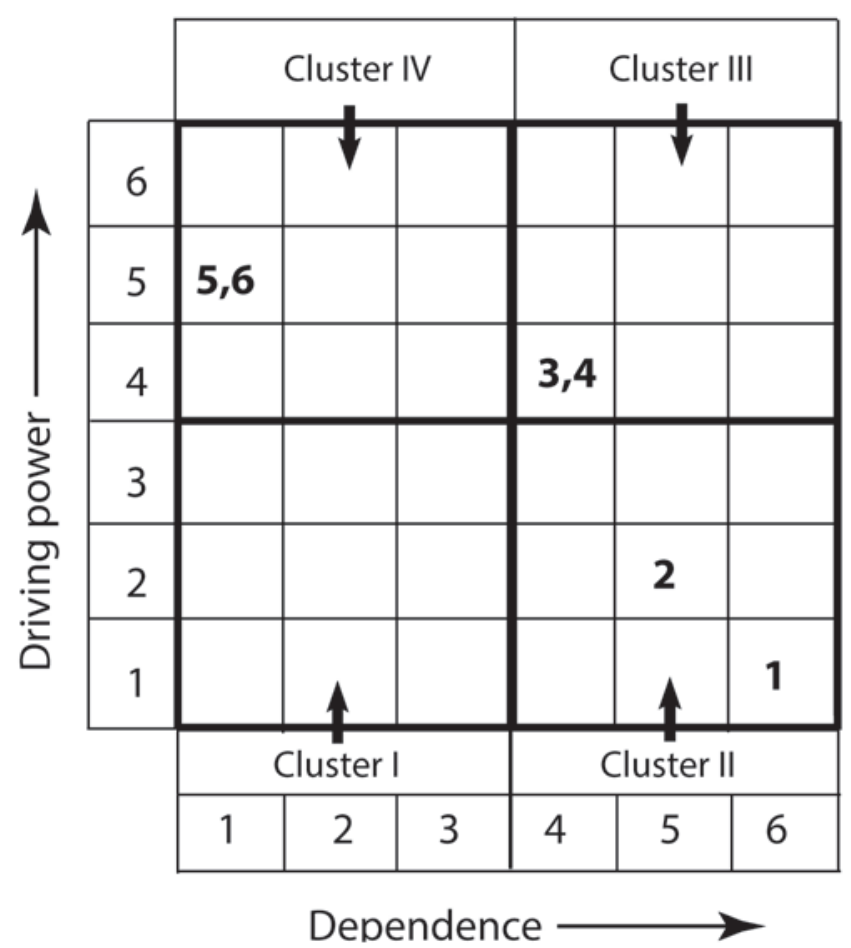

Figure 20: MICMAC analysis.

McCabe in 1976 [48]. Mathematically, the cyclomatic complexity, $\mathrm{M}$, is calculated by the following equation.

$$
M=E-N+2 P
$$

Where $E$ is the number of edges of the digraph, $N$ is the number of nodes of the digraph, and $\mathrm{P}$ is the number of connected components. Usually $P$ is equal to 1.

For the case study-I, from Figure 4, we have $\mathrm{E}=8$ and $\mathrm{N}=6$. Then from Equation (1),

$$
M=E-N+2 P=8-6+2 \times 1=4
$$

A higher numbers of cyclomatic complexity, $M$ means that the process complexity will be difficult to understand and handle. McCabe stated that, "The particular upper bound that has been used for cyclomatic complexity is 10 which seems like a reasonable, but not magical, upper limit." [48] When digraph of JIT supply chain gives anything over a complexity of 10 , we should reconsider the factor's relationships in the SSIM.

Cyclomatic complexity, $M=4$ is less than 10 for the McDonald's JIT supply chain process means that complexity of the process is not hard to understand and managed. Similar analysis can be made for other case studies. The results are:

- For case study of JIT Supply Chain of a Steel Mill, $M=3$

- For case study of JIT-SC Driven Prosthesis, $M$ $=2$

- For case study of JIT-SC of Toyota, $M=7$ 
Aldana M., Anselmi P. D. S., Ayala M., Burns J., Cogdell R., Dilallo C., Drane L., Estevane E., Ethridge B., Fenn K., Gómez, F., Griffith K., Hrechko B., Hudyncia H., Leblanc T., Lugo C. E., McFather E., Miller G., Oneal C., Suesens J., Tocquigny C., Gulbulak U., Ertas, A.

Boosting Just-in-Time Supply Chain Innovation through Additive Manufacturing: A Transdisciplinary Educational Experience

- For case study of JIT-SC of Honda, $M=4$

As seen from the results, Toyota has the most complex JIT supply chain process compared with others. Also results show that cyclomatic complexity of all the case studies are below 10 - means that the complexity of JIT supply chain processes are not difficult to understand and managed. However, even though cyclomatic complexity is less than 10, JIT supply chain process requires complicated planning and considerable experience in this field to overcome complex issues. When digraph gives anything over a complexity of 10, we should reconsider the factor's relationships in the SSIM.

\section{Conclusions}

This student project brings together a diversity of experience and study in the development of this paper - draws together a variety of transdisciplinary fields on JIT-SC integration with AM. The impact of AM on JIT-SC has been investigated in food, steel, bio, and vehicle industries. Results of student resaerch teams revealed that AM will have positive impact on JIT-SC process.

In class, three times Collective Intelligence Management Workshops (CIMW) on the research topics of five research teams (total 20 students) have been organized. Depending on the selected research task by the student teams, they introduced their project proposals (concepts) about the JIT-SC problem being explored. Through "collective impact" (extensive literature search and use of experts) project team members experienced the mutual understanding and learning that are an integral part of the "Transdisciplinary Research Process (TRP)." Students engaged in CIMW activity are exposed to a real sharing of ideas and information, and therefore are actively learned about the selected research project at hand. Since research projects were created participatively, genuine commitment among the research team members were achieved.

It is interesting to note that research sub-project teams of six (each sub-project team had minimum of three and maximum of five students) with specific research tasks on JIT-SC were integrated to a one journal paper. Authors of this paper, students and instructors of the class, thought that this is a unique learning approach - students learned how to implement transdisciplinary research process and learned knowledge generation \& integration. This was achieved through following promises among the team members:

- Team members focused on achieving collective results. They hold the team's needs above their own,

- They hold each other accountable for delivery according to their plans. They had high standards for each other,

- They openly discussed conflicting ideas,

- They thrusted each other.

\subsection{Concluding Remarks}

"AM is becoming increasingly more capable of redefining the manufacturing landscape. The existing eco-system for AM has greatly advanced in the areas of design digitization, deposition methods, printer capabilities, component geometry re-imagination, and post processing methods. Big data and machine learning are reaching maturities where they have become capable of assisting in targeted and rapid problem-solving.

Availability of adequate materials designed for the specific purpose of leveraging existing 3D printing technology is a significantly under developed area of AM. Up to now most materials being used in AM are traditional "industry standard materials" in industry standard product forms, primarily powdered metals and wire, that were originally developed for "legacy forming manufacturing methods" namely press-andsinter or metal injection molding. This use of legacy materials adapted for 3D printing technology is resulting in a sub-optimal level of product creation and market adoption for 3D printed industrial components.

Design wholly new "additive materials" that will complement and maximize the virtues of existing 3D printing technology, particularly low energy, highly stable technologies such as binder jetting. This new material would achieve the required performance properties of an industrial component design but with new or significantly reformulated molecular compositions. Furthermore, the material development process would be synthesized with rapid problem-solving computational methods, support by 
Aldana M., Anselmi P. D. S., Ayala M., Burns J., Cogdell R., Dilallo C., Drane L., Estevane E., Ethridge B., Fenn K., Gómez, F., Griffith K., Hrechko B., Hudyncia H., Leblanc T., Lugo C. E., McFather E., Miller G., Oneal C., Suesens J., Tocquigny C., Gulbulak U., Ertas, A.

Boosting Just-in-Time Supply Chain Innovation through Additive Manufacturing: A Transdisciplinary Educational Experience

the continued expansion of Artificial Intelligence algorithms and its supporting ecosystem." [personal communication with Mr. Jim McCarley former CEO of ExOne 3D printing Company].

\section{Acknowledgement}

We would like to show our gratitude to Mr. Jim McCarley for encouraging us to develop Additive Manufacturing course in the Mechanical Engineering Department at Texas Tech University.

Author Contributions: Paper was written collaboratively by the authors.

Funding: This research received no external funding.

Conflicts of Interest: The authors declare no conflict of interest.

\section{References}

[1] Ertas, A., (2018). Transdisciplinary Engineering Design Process. John Wiley \& Sons NJ 07030.

[2] Paul Witherell, Albert Jones, and Yan Lu, (2017). Additive Manufacturing: A Trans-disciplinary Experience. from book Transdisciplinary perspectives on complex systems: New findings and approaches (pp.145-175), DOI: 10.1007/978-3-319-38756-7_6.

[3] Sadeghi, Javad; Mousavi, Seyed Mohsen; Niaki, Seyed Taghi Akhavan (2016-08-01). Optimizing an inventory model with fuzzy demand, backordering, and discount using a hybrid imperialist competitive algorithm. Applied Mathematical Modelling, 40 (15-16): 7318-7335. doi:10.1016/j.apm.2016.03.013. ISSN 0307-904X

[4] Additive Manufacturing: JIT Parts and Service Solutions for the Next Industrial Revolution. https://ic3dprinters.com/additivemanufacturing-jit-parts-service-solutions-nextindustrial-revolution/. Accessed October 7, 2019.

[5] 3D opportunity for the supply chain: Additive manufacturing delivers (Deloitte), (2015). https://www2.deloitte.com/us/en/insights/focus/3dopportunity/additive-manufacturing-3d-printingsupply-chain-transformation.html. Accessed October 5, 2019.

[6] Ertas, A.,(2010). Understanding of Transdiscipline and Transdisciplinary Process. Transdisciplinary Journal of Engineering 85 Science, 1(1), pp. 1-12.
[7] Nicolescu, B., (2010). Methodology of Transdisciplinarity-Levels of Reality, Logic of the Included Middle and Complexity. Transdisciplinary Journal of Engineering \&3 Science, vol 1, pp. 17-32.

[8] Nicolescu, B., (2002). Manifesto of transdisciplinarity. State University of New York Press, Albany.

[9] Stokols, D. (2006). Toward a Science of Transdisciplinary Action Research. Am J Community Psychol, 38, pp. 6377. DOI 10.1007/s10464-006-9060-5.

[10] Klein, T. J., (2008). Evaluation of interdisciplinary and transdisciplinary research: a literature review. American Journal of Preventive Medicine, 35(2), pp.S116-S123.

[11] Pohl, C., (2010). From Transdisciplinarity to Transdisciplinary Research, Transdisciplinary Journal of Engineering \&3 Science, Vol 1, pp. 65-73.

[12] Lawrence, J. R., (2010). Deciphering Interdisciplinary and Transdisciplinary Contributions. Transdisciplinary Journal of Engineering \&3 Science, Vol 1, pp. 11-116.

[13] McGregor, S., (2018). Deciphering Interdisciplinary and Transdisciplinary Contributions. Transdisciplinary Journal of Engineering \& Science, Vol 9, pp. 182-198.

[14] Brenner, E. J., (2013). Systems and Information: A Transdisciplinary Study. Transdisciplinary Journal of Engineering 83 Science, Vol 4, pp. 1-20.

[15] Gehlert, S., (2013). Shaping Education and Training to Advance Transdisciplinary Health Research. Transdisciplinary Journal of Engineering \& Science, Vol 3, pp. 1-10.

[16] Dieleman, H., (2012). Transdisciplinary Artful Doing in Spaces of Experimentation and Imagination. Transdisciplinary Journal of Engineering \& Science, Vol 3, pp. 44-57.

[17] Adame, D., (2011). From a Disciplinary to a Transdisciplinary Vision of the University: A Space of Knowledge, Culture, Art, Spirituality, and Life. Transdisciplinary Journal of Engineering \& Science, Vol 2, pp. 33-39.

[18] Kollman T. and Ertas, A., (2010). Results of a Survey to Identify Differences between Interdisciplinary and Transdisciplinary Research Processes. Transdisciplinary Journal of Engineering \&5 Science, 1(1), pp.131- 141.

[19] Ertas, A., (2012). Integrating Transdisciplinarity in Undergraduate Education. Transdisciplinary Journal of Engineering $\mathscr{E}$ Science, 3(1), pp. 128-144. 
Aldana M., Anselmi P. D. S., Ayala M., Burns J., Cogdell R., Dilallo C., Drane L., Estevane E., Ethridge B., Fenn K., Gómez, F., Griffith K., Hrechko B., Hudyncia H., Leblanc T., Lugo C. E., McFather E., Miller G., Oneal C., Suesens J., Tocquigny C., Gulbulak U., Ertas, A.

Boosting Just-in-Time Supply Chain Innovation through Additive Manufacturing: A Transdisciplinary Educational Experience

[20] Ertas, A., (2016). Transdisciplinary Trans-Sector Integration in Education: Convergence. Transdisciplinary Journal of Engineering $\&$ Science, 6(1), pp. $24-37$.

[21] Ertas, A., Rohman, J., Chillakanti, P., Baturalp, T. B., (2015). Transdisciplinary Collaboration as a Vehicle for collective Intelligence: A Case Study of Engineering Design Education. International Journal of Engineering Education, 31(6A), pp. 1526-1536.

[22] Mahajan, V.B., Jadhav, J.R., Kalamkar, V.R., and Narkhede, B.E., (2013). Interpretive structural modelling for challenging issues in JIT supply chain: Product variety perspective. International Journal of Supply Chain Management, 2(4), pp. 5063.

[23] J. N. Warfield, (1974). Developing Interconnected Matrices in Structural Modeling. IEEE Transactions on Systems, Man and Cybernetic, 4(1), 1974, pp. 5158 .

[24] Ertas, A., et al. (2015). Transdisciplinary Collaboration as a Vehicle for Collective Intelligence: A Case Study of Engineering Design Education. International Journal of Engineering Education vol. 31 pp. 15261536.

[25] F. Harary, R. V. Norman, and D. Cartwright (1965). Structural Models: An Introduction to the Theory of Directed Graphs. Willey, New York, 1965.

[26] 40 Interesting facts about McDonald's. Serious Facts, Serious Facts, 2017, https://www.seriousfacts.com/mcdonalds-facts/ (Accessed on 10/11, 2019)

[27] "Mc Donald's Fast Food Restaurant JIT." OPEP, OPEP, IIM Raipur, 25 June 2011, http://opepiimraipur.blogspot.com/2011/06/mcdonalds-fast-food-restaurant-jit.html. Accessed October 11, 2019

[28] Carlota, V. (2019). McDonald's will offer completely 3D printed burgers by 2020. 3Dnatives, 3Dnatives, 1 April 2019, https://www.3dnatives.com/en/mcdonalds-3dprinting-010420195/

[29] Zijm, W.H.M. \& Knofius, Nils \& van der Heijden, Matthieu. (2019). Additive Manufacturing and Its Impact on the Supply Chain. 10.1007/978-3-31992447-2_23.

[30] Clarke, Corey, (2017). Mcdonald's Reinvents the Straw with 3d Printing. 3D Printing Industry, 3D Printing Industry, 15 February 2017. https://3dprintingindustry.com/news/mcdonaldsreinvents-straw-3d-printing-105772/. Accessed October 11, 2019.

[31] Moss, Caroline, (2013). McDonalds Wants To Start 3D Printing Happy Meal Toys For Unhappy
Kids. Business Insider, Insider Inc, 6 November 2013, https://www.businessinsider.com/mcdonaldswants-3d-printers-2013-11. Accessed October 11, 2019.

[32] Brooke, David,(1986). The Advent of the Steel Rail. Journal of Transport History, 7(1), pp 18-31.

[33] Lloyd-Jones, Ro; et al. (1998). British Industrial Capitalism Since the Industrial Revolution. Psychology Press. p. 93.

[34] Milward, Alan; S. B. Saul, (2012). The Development of the Economies of Continental Europe 1850-1914. Routledge. p. 96.

[35] World Coal (2019). How Is Steel Produced? World Coal Association, www.worldcoal.org/coal/usescoal/how-steel-produced. Accessed October 11, 2019.

[36] Tommelein, Iris D, and Markus Weissenberger, (1999). More just-in-time: location of buffers in structural steel supply and construction processes. Semantic Scholar, University of California, Berkeley, pdfs.semanticscholar.org/60b7/b97c15200b8de03b75 43489e8e278ca77467.pdf. Accessed October 11, 2019.

[37] Laureijs, R. E., Roca, J. B., Narra, S. P., Montgomery, C., Beuth, J. L., and Fuchs, E. R. H., (2017). Metal Additive Manufacturing: Cost Competitive Beyond Low Volumes. ASME. J. Manuf. Sci. Eng. August 2017; 139(8): 081010. https://doi.org/10.1115/1.4035420.

[38] Subcommittee on Advance Manufacturing (2018). Strategy for American Leadership in Advanced Manufacturing. Whitehouse.gov, pp. 1114, www.whitehouse.gov/wpcontent/uploads/2018/10/Advanced-

Manufacturing-Strategic-Plan-2018.pdf.

[39] Secrest, R. (2019). How Products are Made, Artificial Limb. http://www.madehow.com/Volume1/Artificial-Limb.html, Accessed September 27, 2019.

[40] Reidel, H. (2019). PreScouter. https://www.prescouter.com/2017/07/3d-printedprosthetics/ Accessed September 27, 2019.

[41] Delozier, Liz., (2018). 3D Printing Toyota's Headlights: The Sourcing Decision. Technology and Operations Management, digital.hbs.edu/platformrctom/submission/3d-printing-toyotas-headlightsthe-sourcing-decision/. Accessed October 11, 2019.

[42] Krassenstein E., (2015). Toyota to Let People 3D Print Custom Parts for Vehicles in Japan with the Open Road Project. 
Aldana M., Anselmi P. D. S., Ayala M., Burns J., Cogdell R., Dilallo C., Drane L., Estevane E., Ethridge B., Fenn K., Gómez, F., Griffith K., Hrechko B., Hudyncia H., Leblanc T., Lugo C. E., McFather E., Miller G., Oneal C., Suesens J., Tocquigny C., Gulbulak U., Ertas, A.

Boosting Just-in-Time Supply Chain Innovation through Additive Manufacturing: A Transdisciplinary Educational Experience

https://3dprint.com/63477/toyota-3d-printedvehicle/. Accessed October 11, 2019.

[43] AL Nasser, A. M. (n.d.). https://www.ijser.org/paper/Honda-SupplyChain.html. Accessed October 12, 2019.

[44] Anonymous 678. (n.d.). (2018). Honda: Paving the Way with Additive Manufacturing. https://digital.hbs.edu/platform-rctom/ submission/honda-paving-the-way-with-additivemanufacturing/. Accessed Octoner 12, 2019.

[45] What is Just-In-Time Inventory Management? (2013, December 28). http://www.financeinanswers. com/what-is-just-in-time-inventory-management/. Accessed Octoner 12, 2019.

[46] Honda Shifts its Customization Options into High Gear with 3D Printing. (2018, December 18). https://www.javelin-tech.com/3d/honda3d-printing-auto-accessories/. Accessed Octoner 12, 2019.

[47] McCabe, T. J., (1976). Describing Cyclomatic Complexity, IEEE Transactions on Software Engineering, Vol. 2, No. 4, p. 308. 